Supporting Information

\title{
Targeted Nanoparticles for the Delivery of Novel Bioactive Molecules to Pancreatic Cancer Cells
}

Vanna Sanna, ${ }^{\dagger}, \mid$ Salvatore Nurra,${ }^{\dagger}$ Nicolino Pala,${ }^{\dagger}$ Salvatore Marceddu,${ }^{\S}$ Divya Pathania, ${ }^{\perp}$ Nouri Neamati, ${ }^{+* *}$ and Mario Sechi ${ }^{\dagger, \|}, *$

${ }^{\dagger}$ Department of Chemistry and Pharmacy, University of Sassari, Italy, and "Laboratory of Nanomedicine, University of Sassari, c/c Porto Conte Ricerche, Alghero, Italy, and ${ }^{\S}$ Istituto di Scienze delle Produzioni Alimentari (ISPA), CNR, sez. di Sassari, Italy, and ${ }^{\perp}$ Department of Pharmacology and Pharmaceutical Sciences, University of Southern California, School of Pharmacy, Los Angeles, CA, USA, and ${ }^{\ddagger}$ Department of Medicinal Chemistry, College of Pharmacy, Translational Oncology Program, University of Michigan, Ann Arbor, MI, United States 


\section{Contents}

Mass, ${ }^{1} \mathrm{H}$, and ${ }^{13} \mathrm{C}$ spectra of compound $\mathbf{1}$

S3-S5

Mass, ${ }^{1} \mathrm{H}$, and ${ }^{13} \mathrm{C}$ spectra of compound 2

S6-S8

Mass, ${ }^{1} \mathrm{H}$, and ${ }^{13} \mathrm{C}$ spectra of compound 7

S9-S11

Mass, ${ }^{1} \mathrm{H}$, and ${ }^{13} \mathrm{C}$ spectra of compound $\mathbf{6}$

S12-S14

Mass, ${ }^{1} \mathrm{H}$, and ${ }^{13} \mathrm{C}$ spectra of compound $\mathbf{5}$

S15-S17

Mass, and ${ }^{1} \mathrm{H}$, spectra of compound $\mathbf{1 1}$

S18-S20

Mass, ${ }^{1} \mathrm{H}$, and ${ }^{13} \mathrm{C}$ spectra of compound $\mathbf{1 0}$

S21-S23

${ }^{1} \mathrm{H}$ spectrum of PLGA-NHS

S24

${ }^{1} \mathrm{H}$ spectrum of PLGA-11

S25

${ }^{1} \mathrm{H}$ spectrum of PLGA-PEG-NH2

S26

${ }^{1} \mathrm{H}$ spectrum of PLGA-PEG-12

S27

${ }^{1} \mathrm{H}$ spectrum of PLGA-PEG-mal

S28

Synthesis of peptide $\mathbf{1 2}$

S29

Mass, HPLC, and ${ }^{1} \mathrm{H}$, spectra of $\mathbf{1 2}$

S30-32

Elemental analyses of compounds 1, 2, 5, 6, 7, 10, and 11

S33

Characterization details of 6-coumarin $(6 C)$ loaded NPs

S34

GPC-SEC analyses for PLGA-A, PLGA-PEG-NH 2 and PLGA-PEG-12 polymers

S35-36 


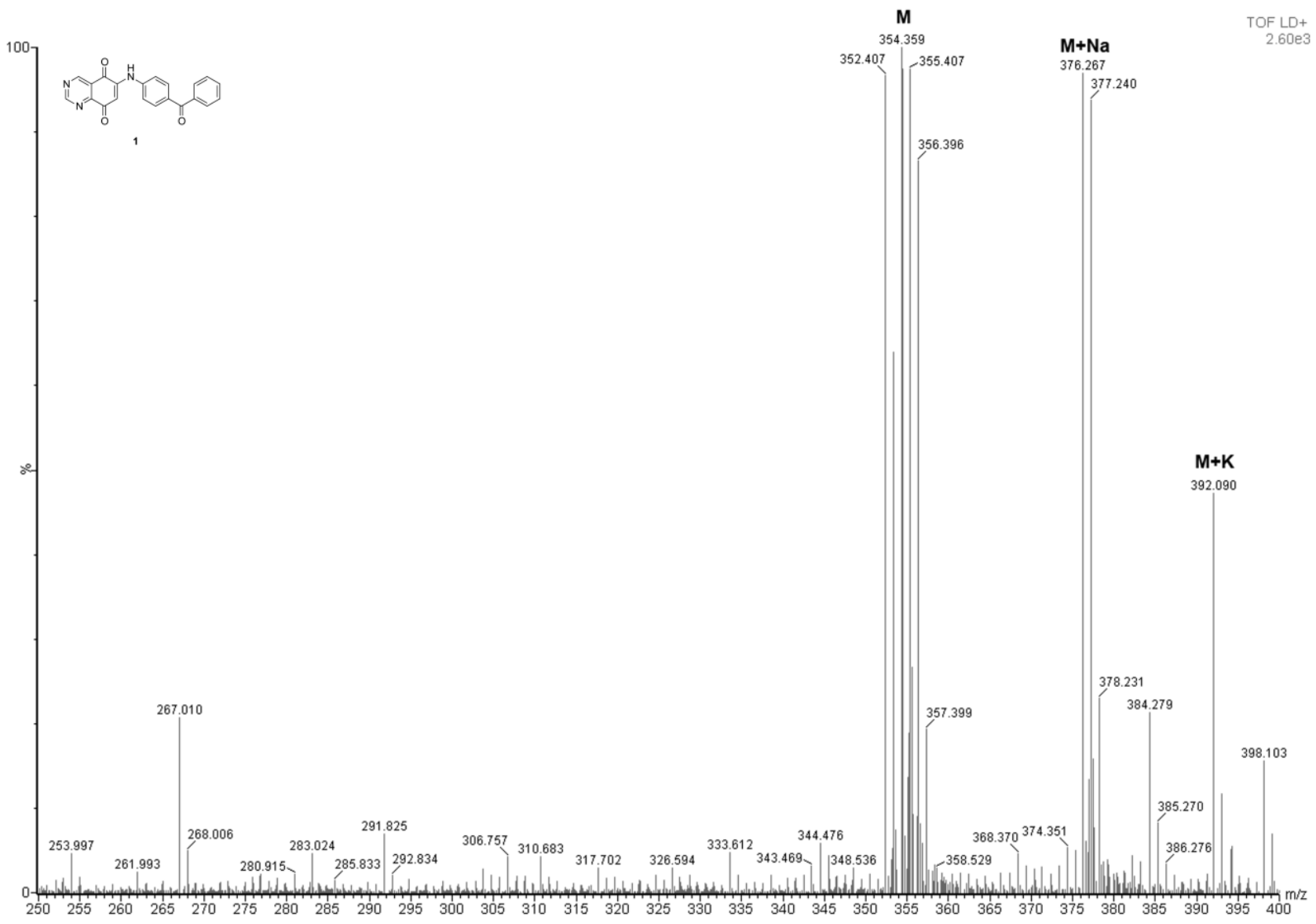




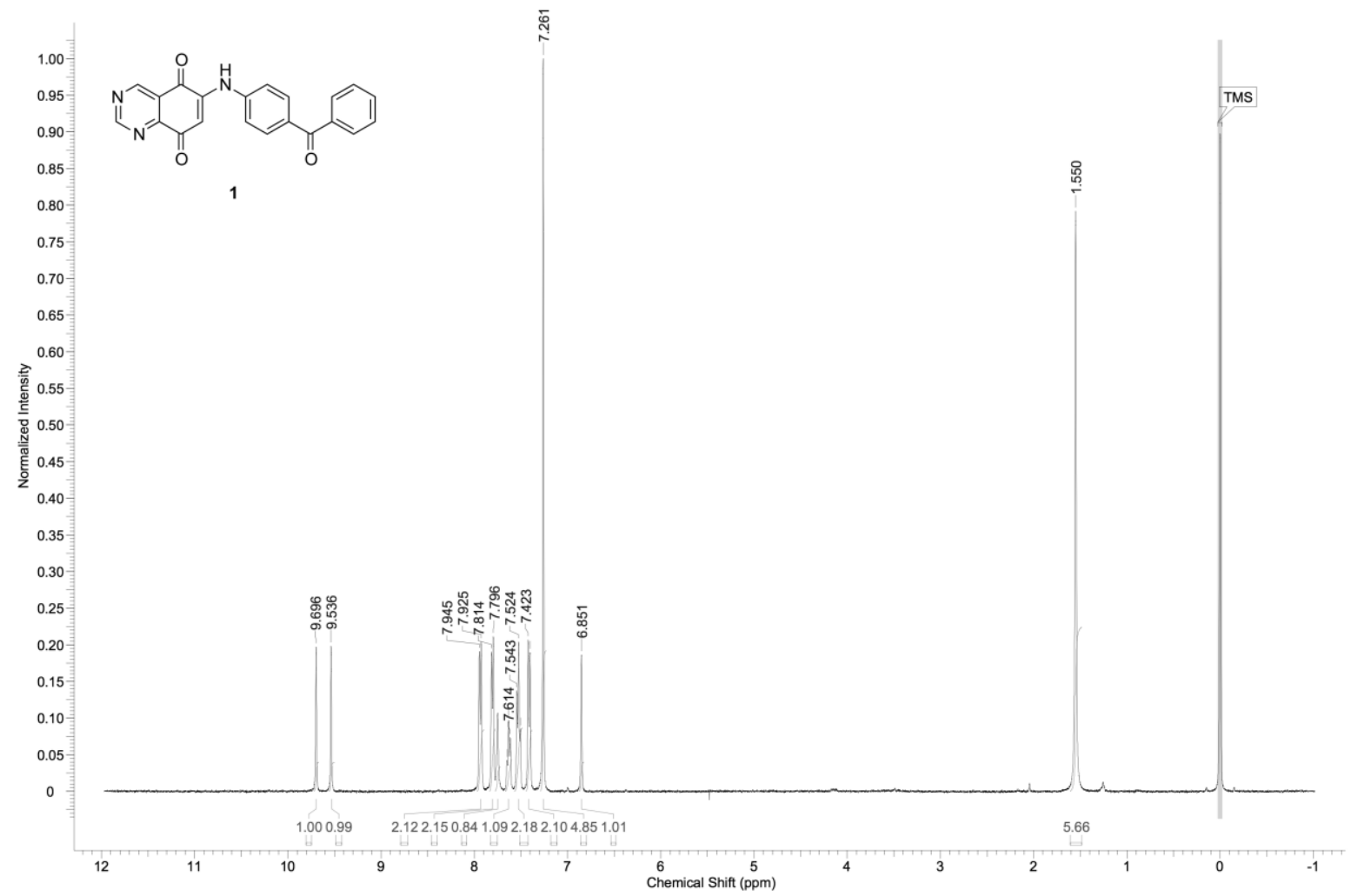




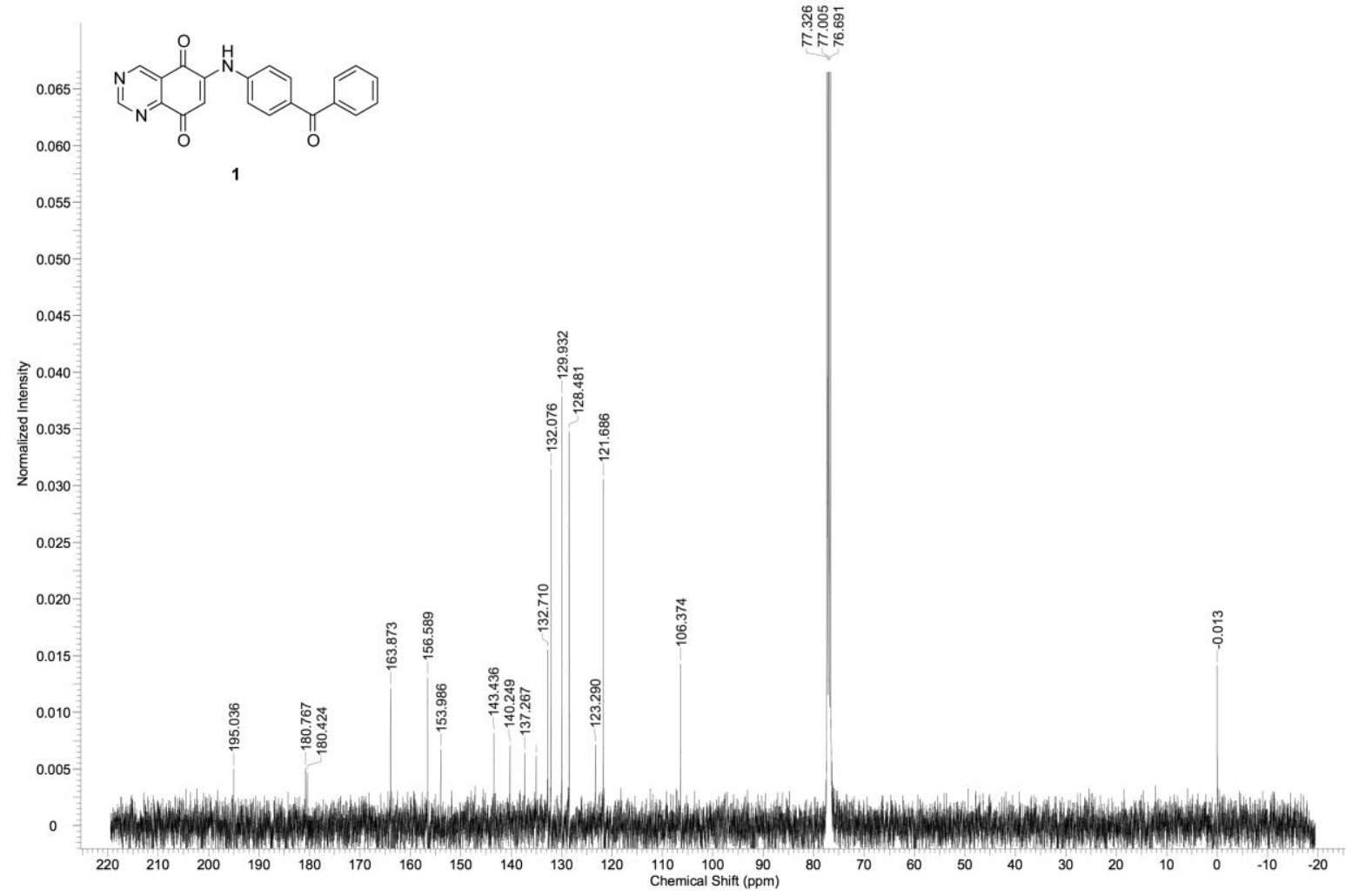




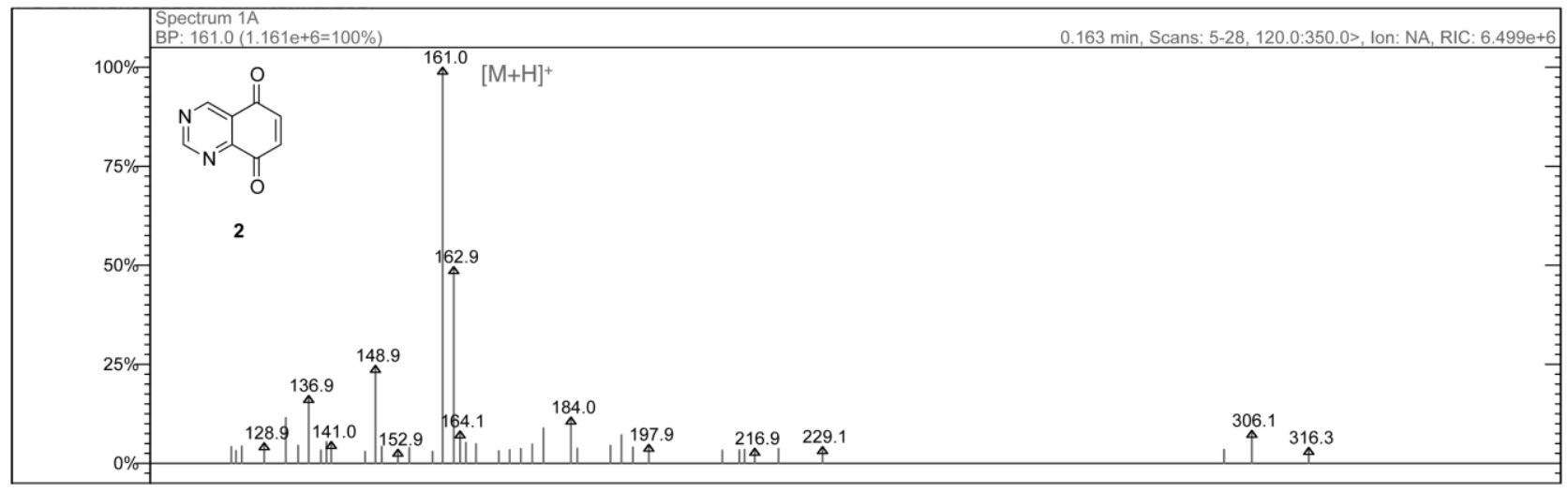




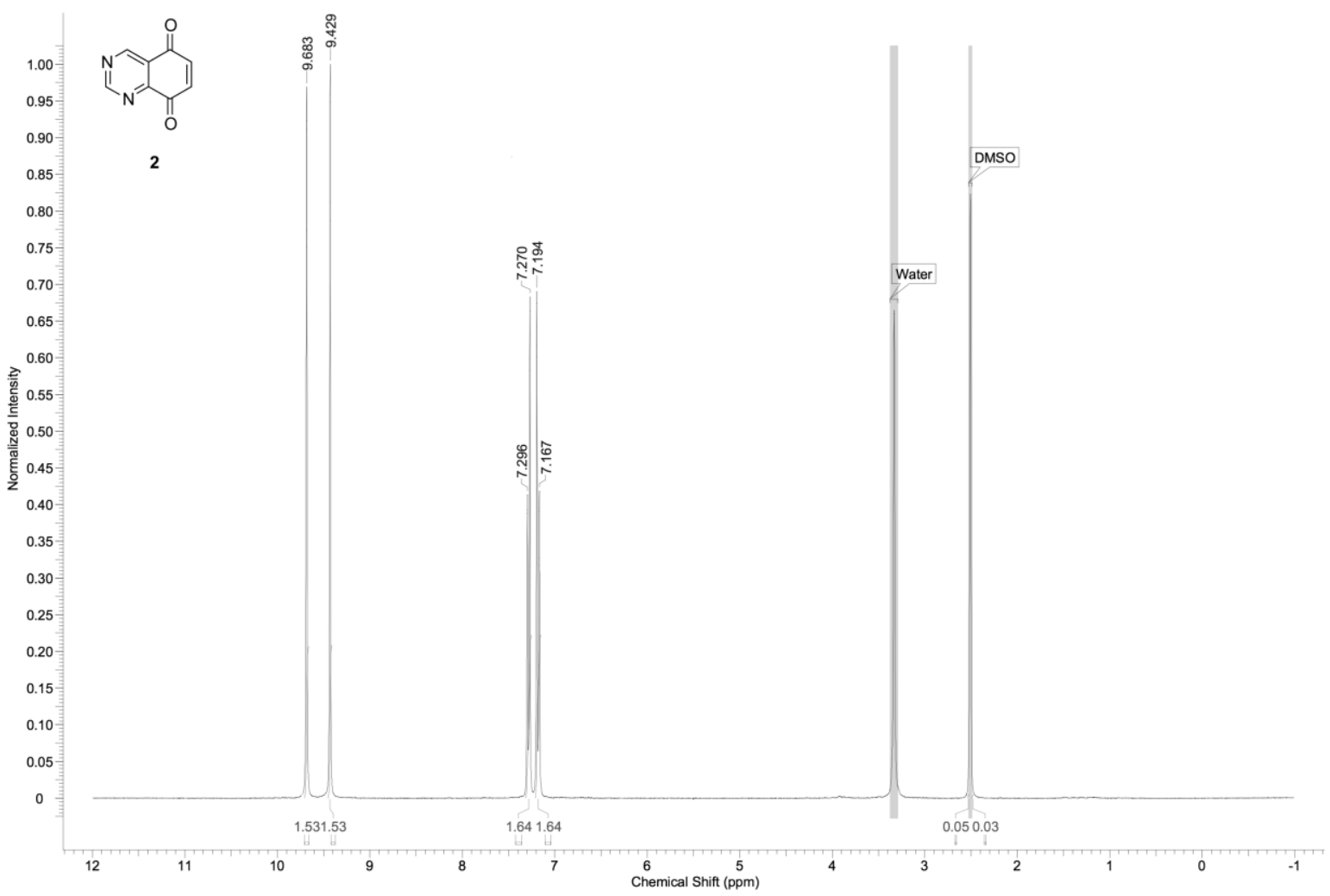




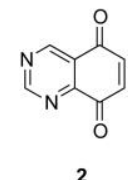

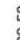

해용

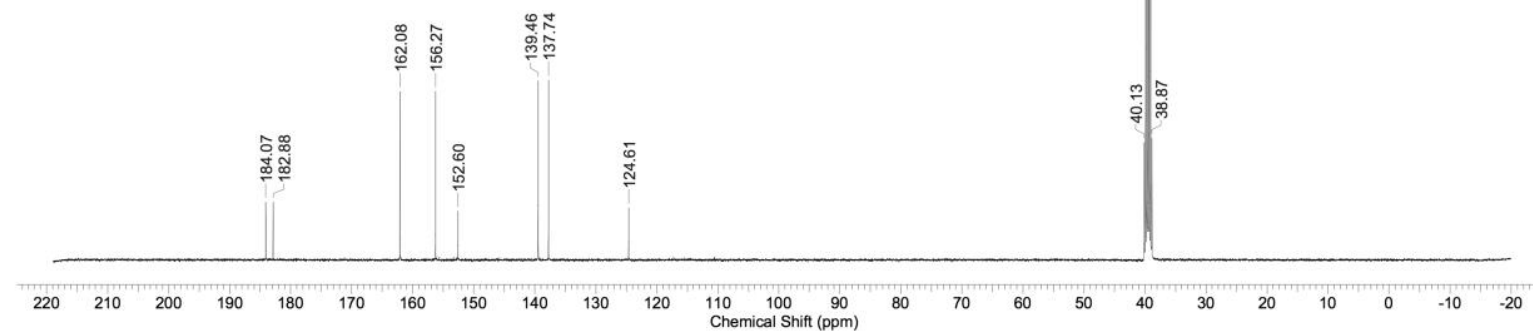




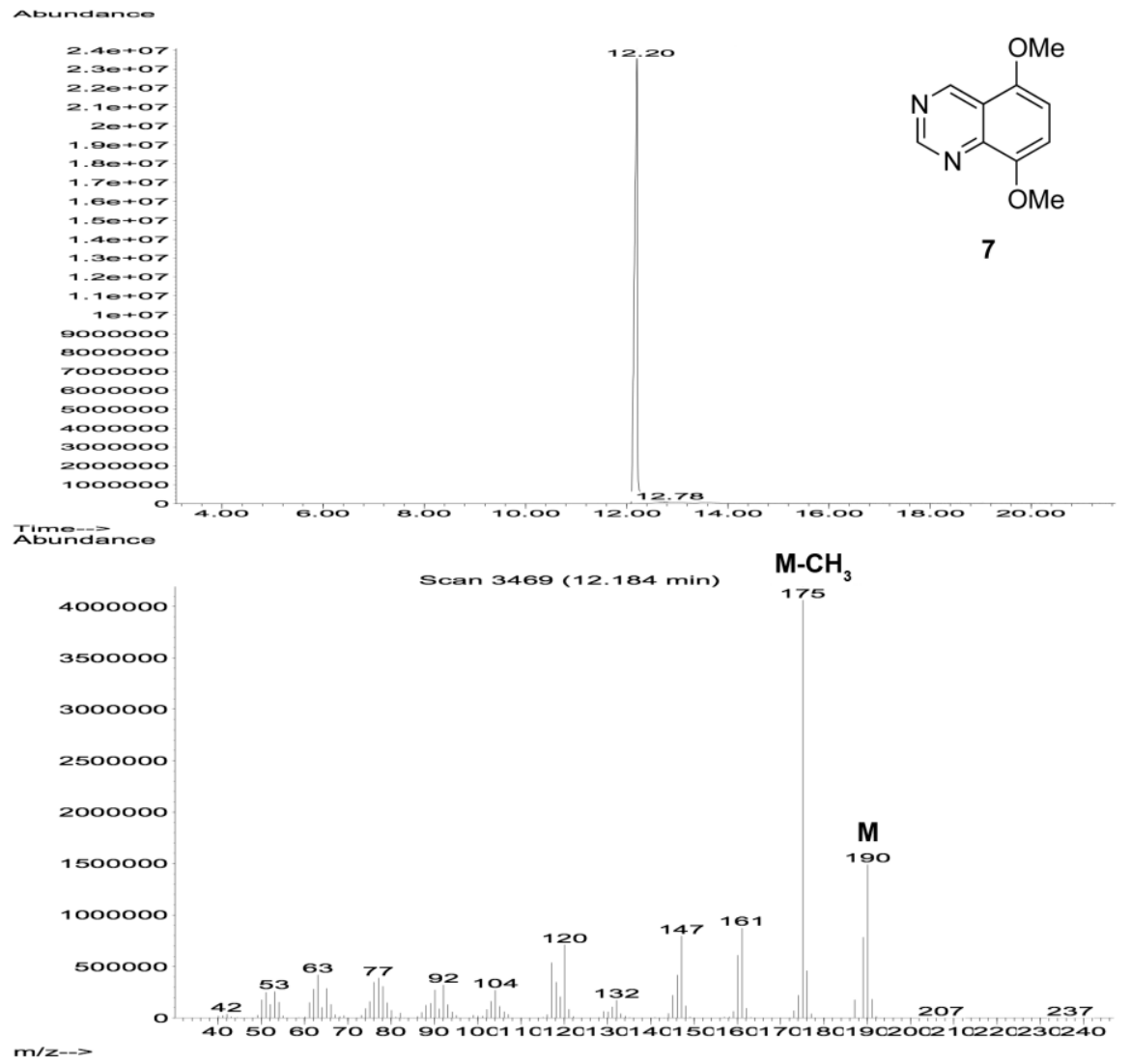

Scan 3469 (12.184 min) 


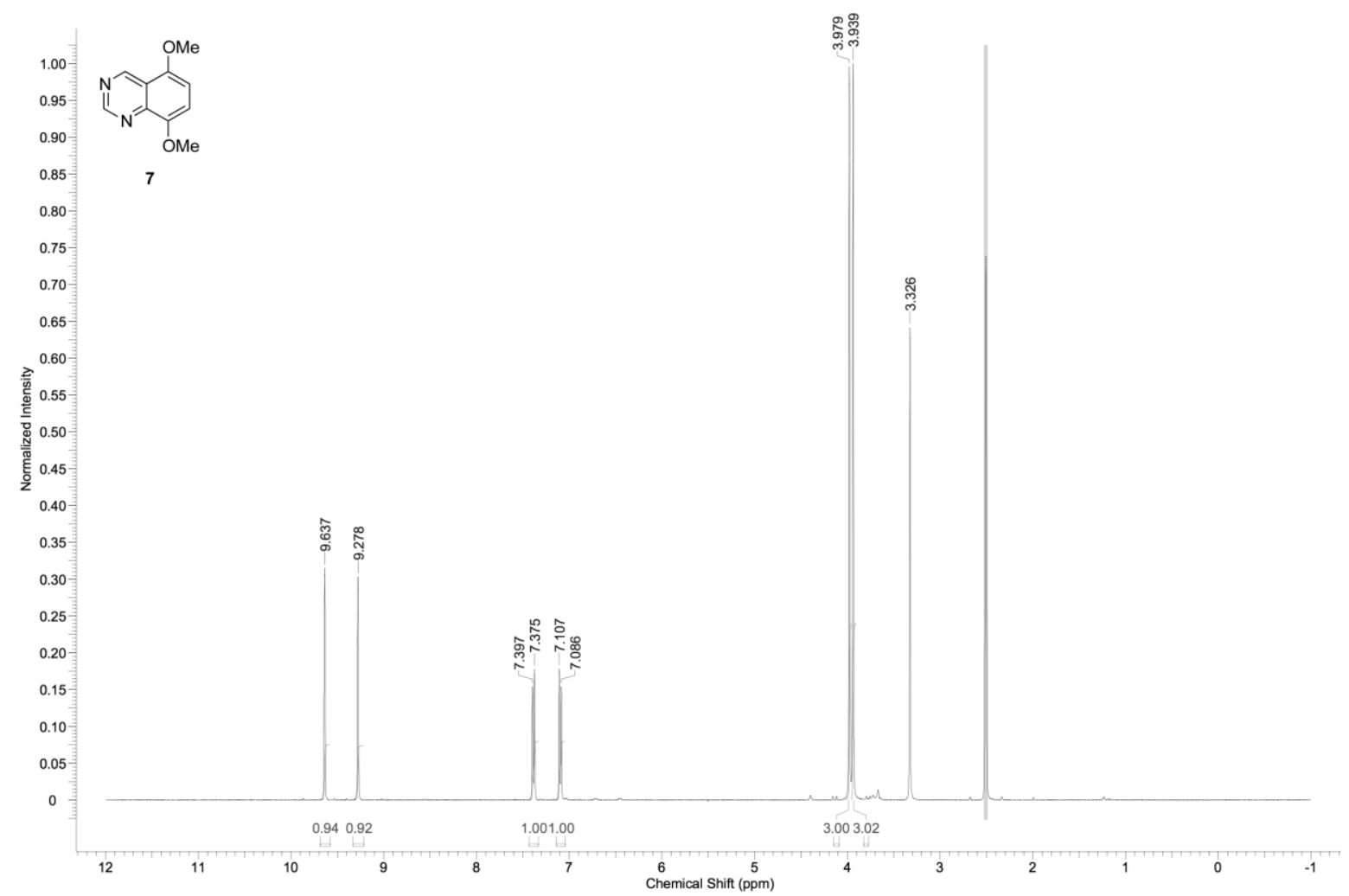




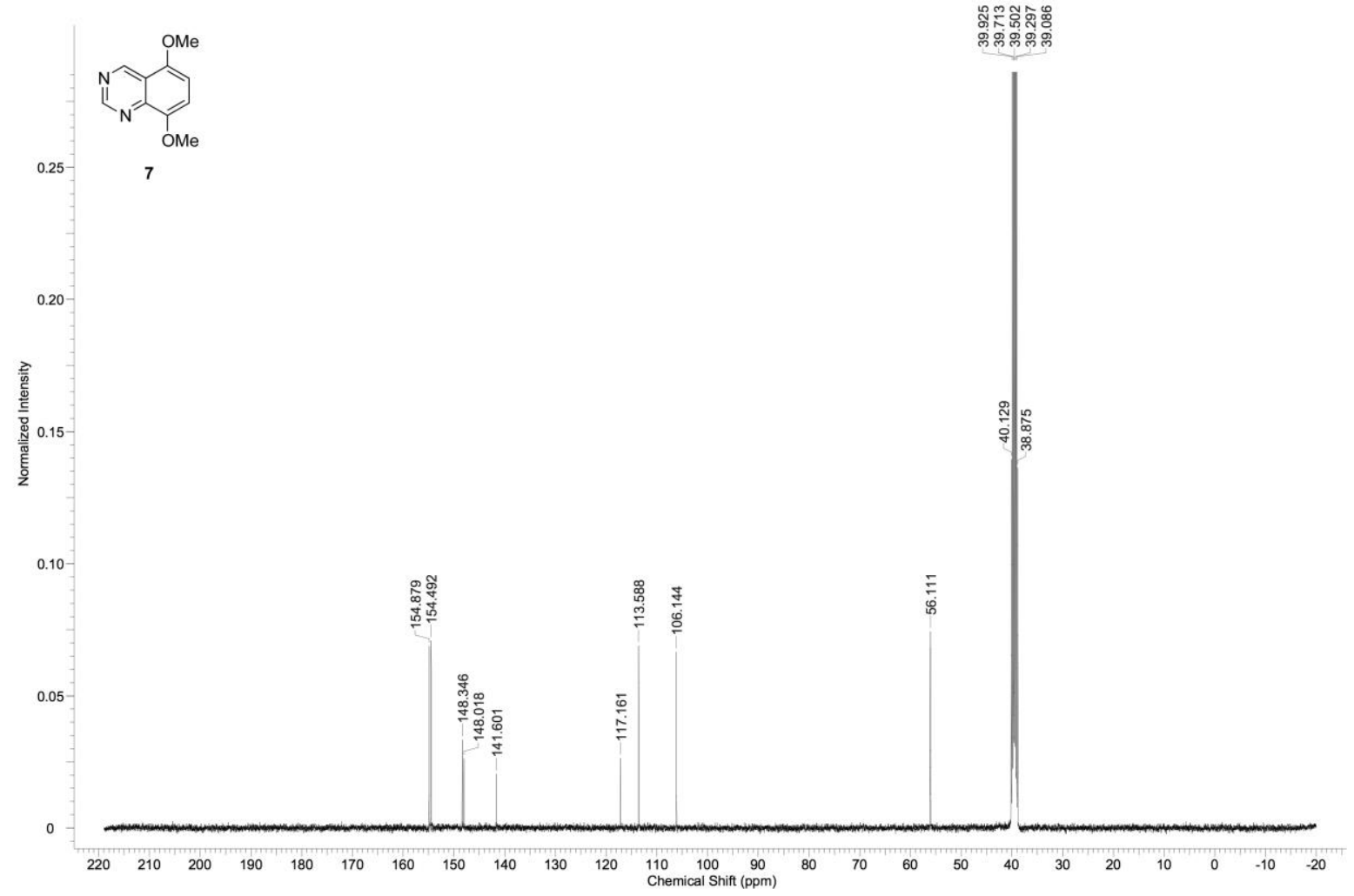




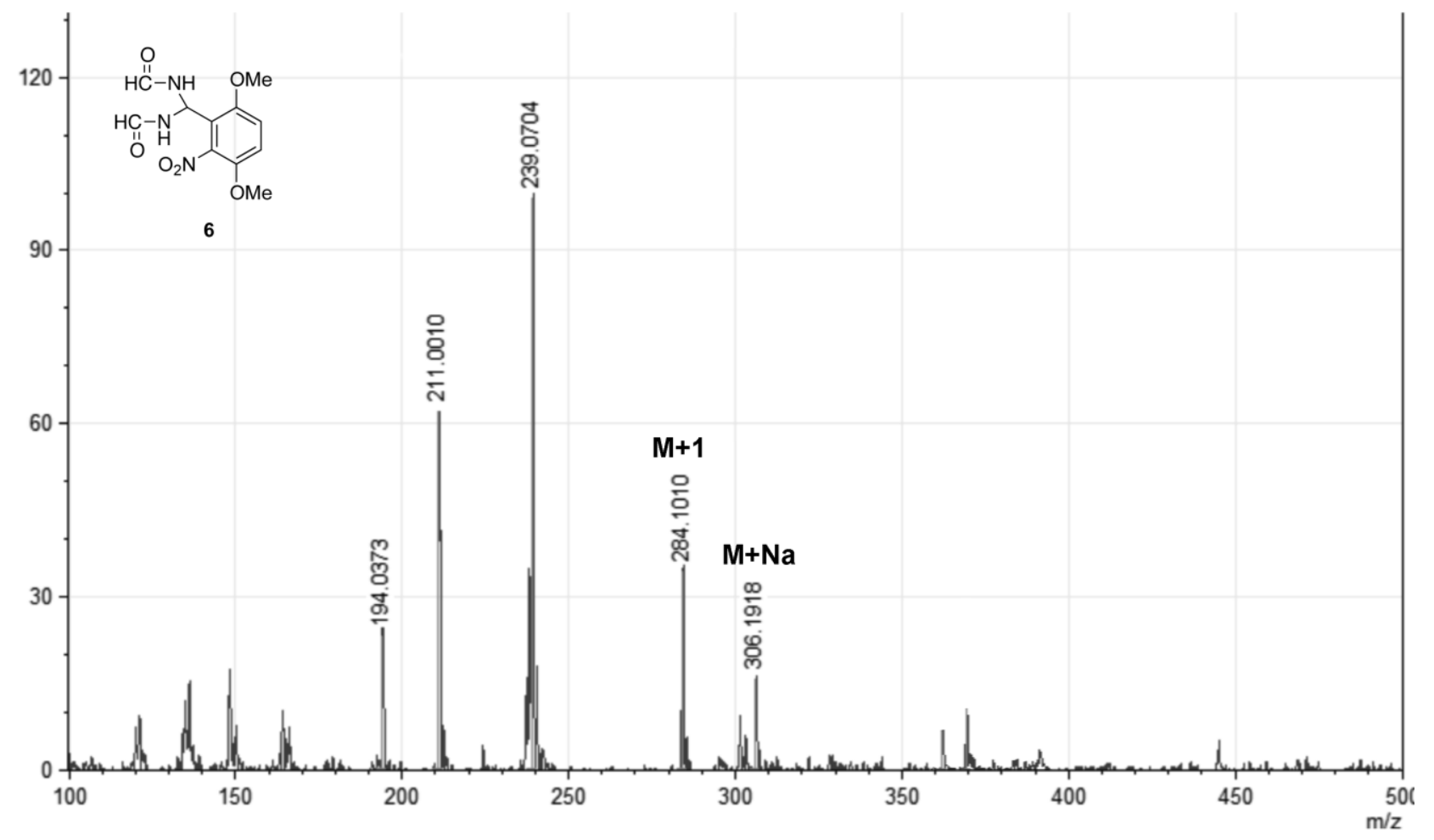




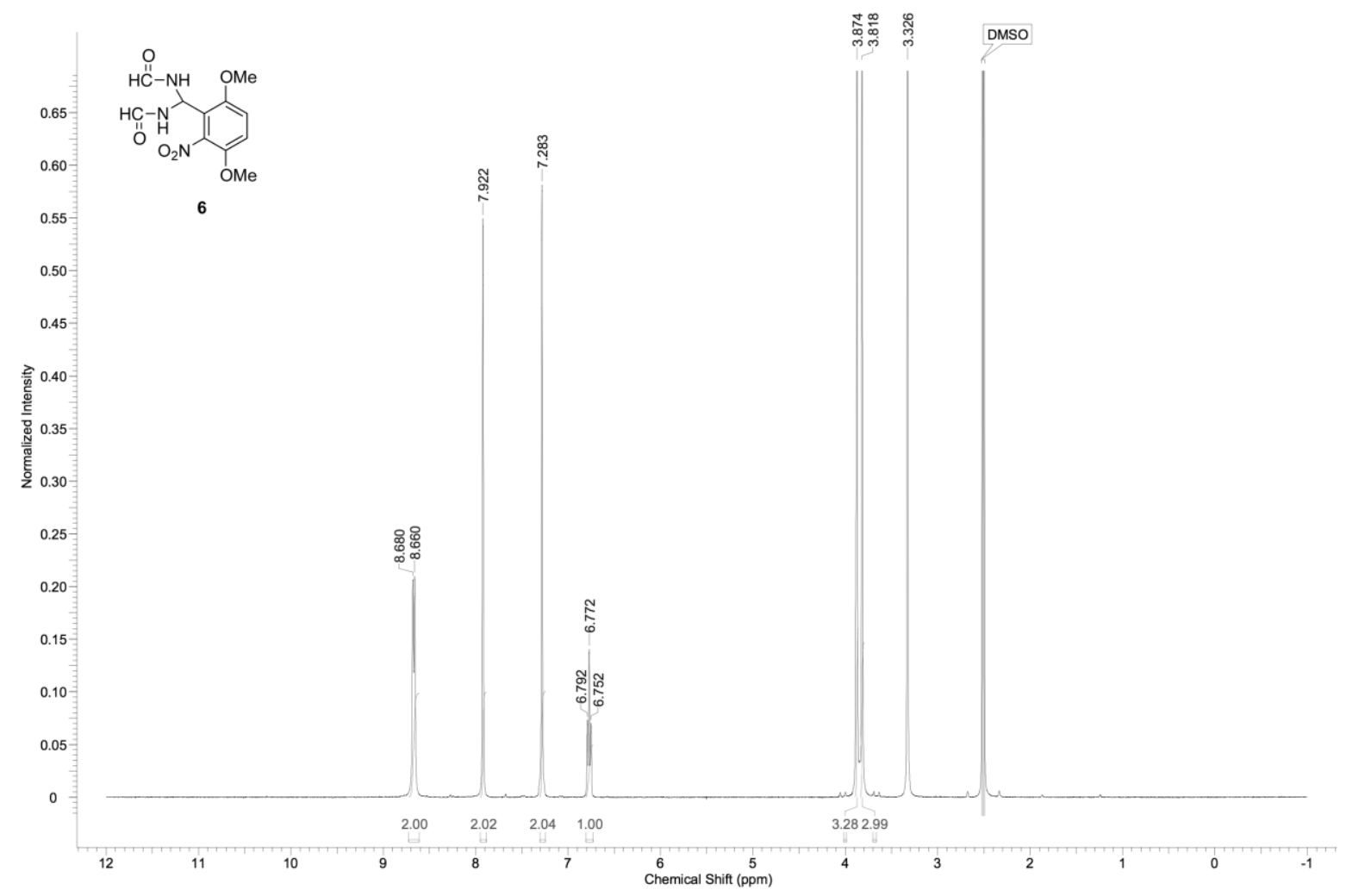




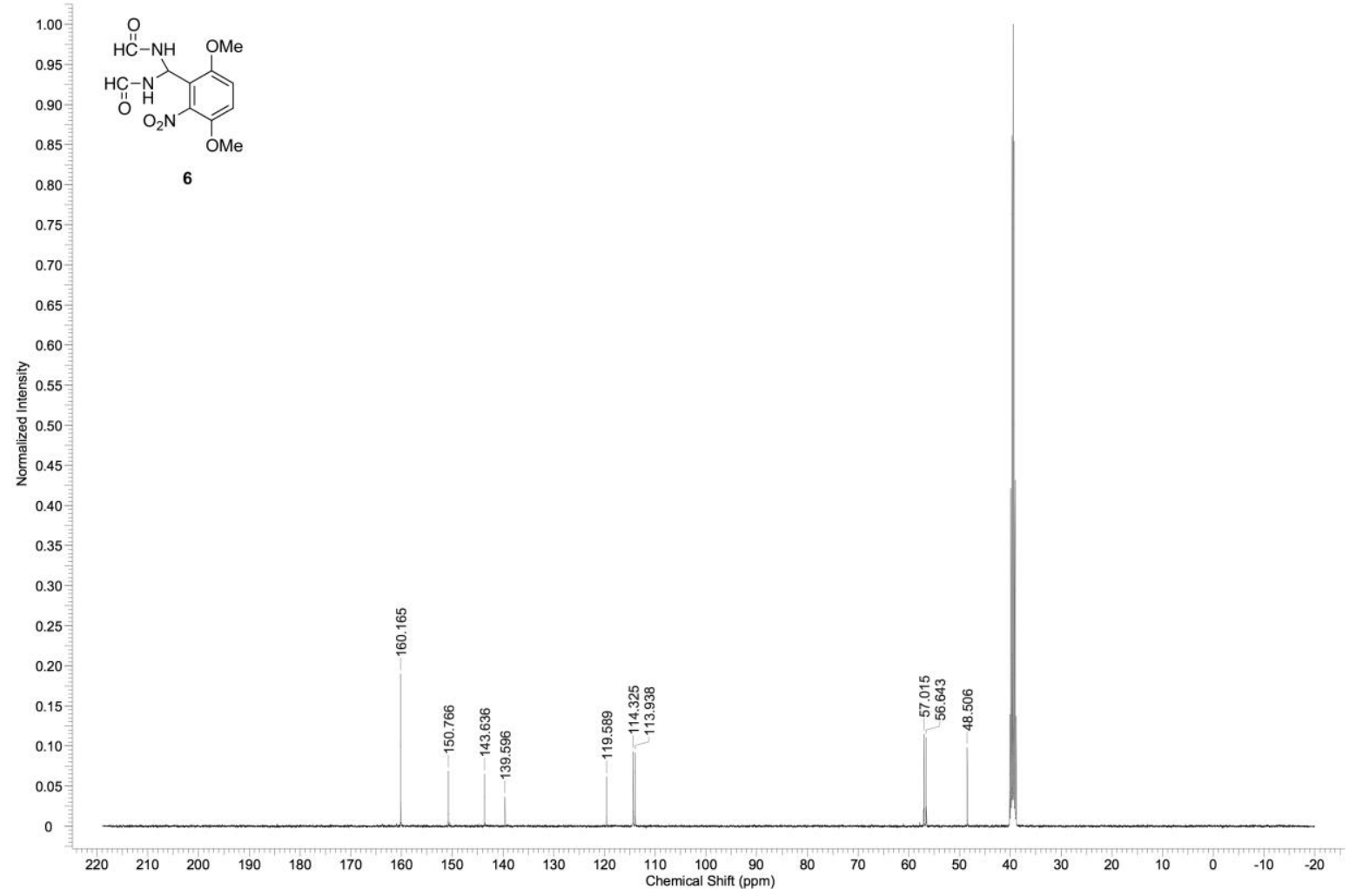




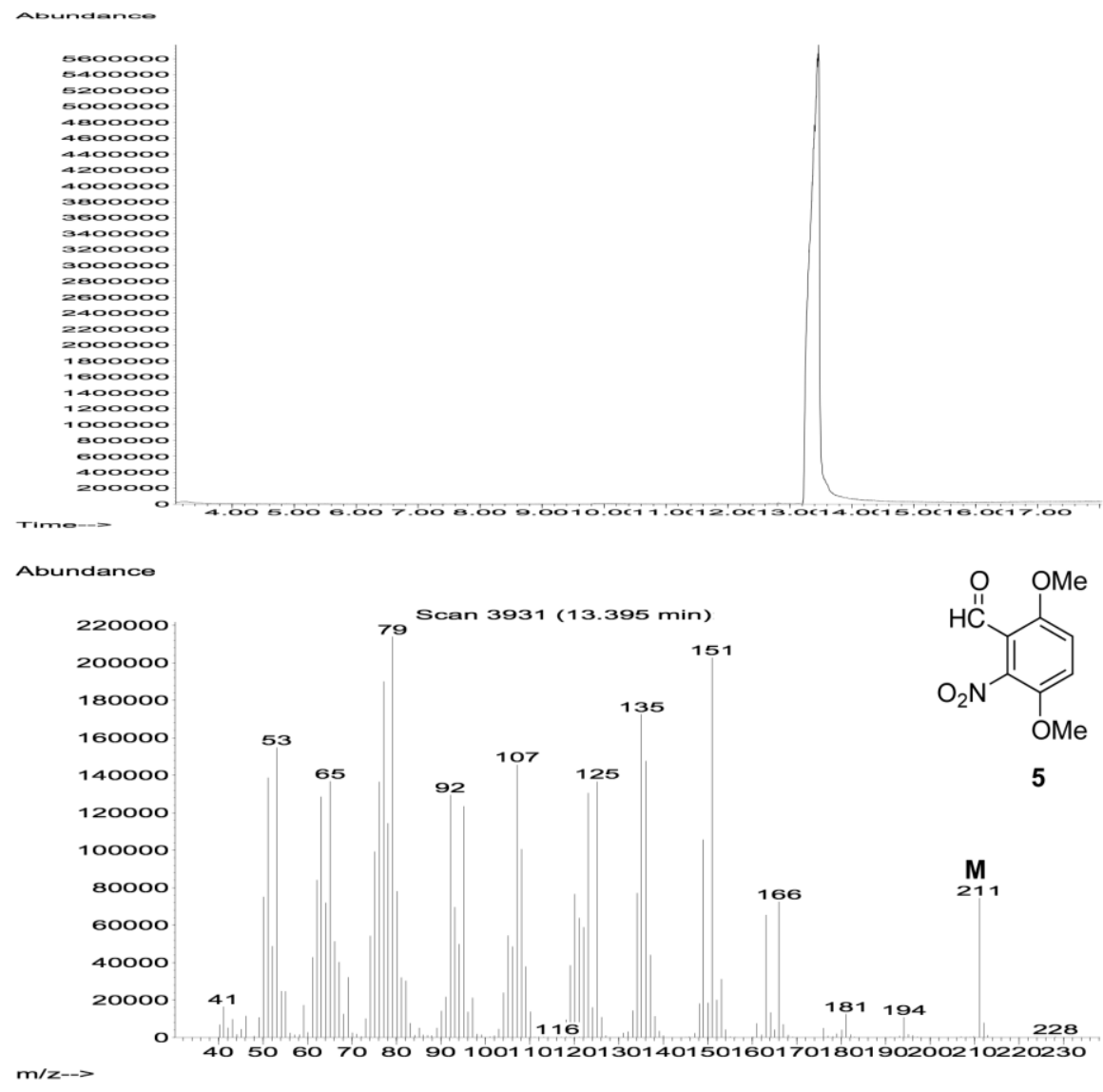

Scan 3931 (13.395 min) 


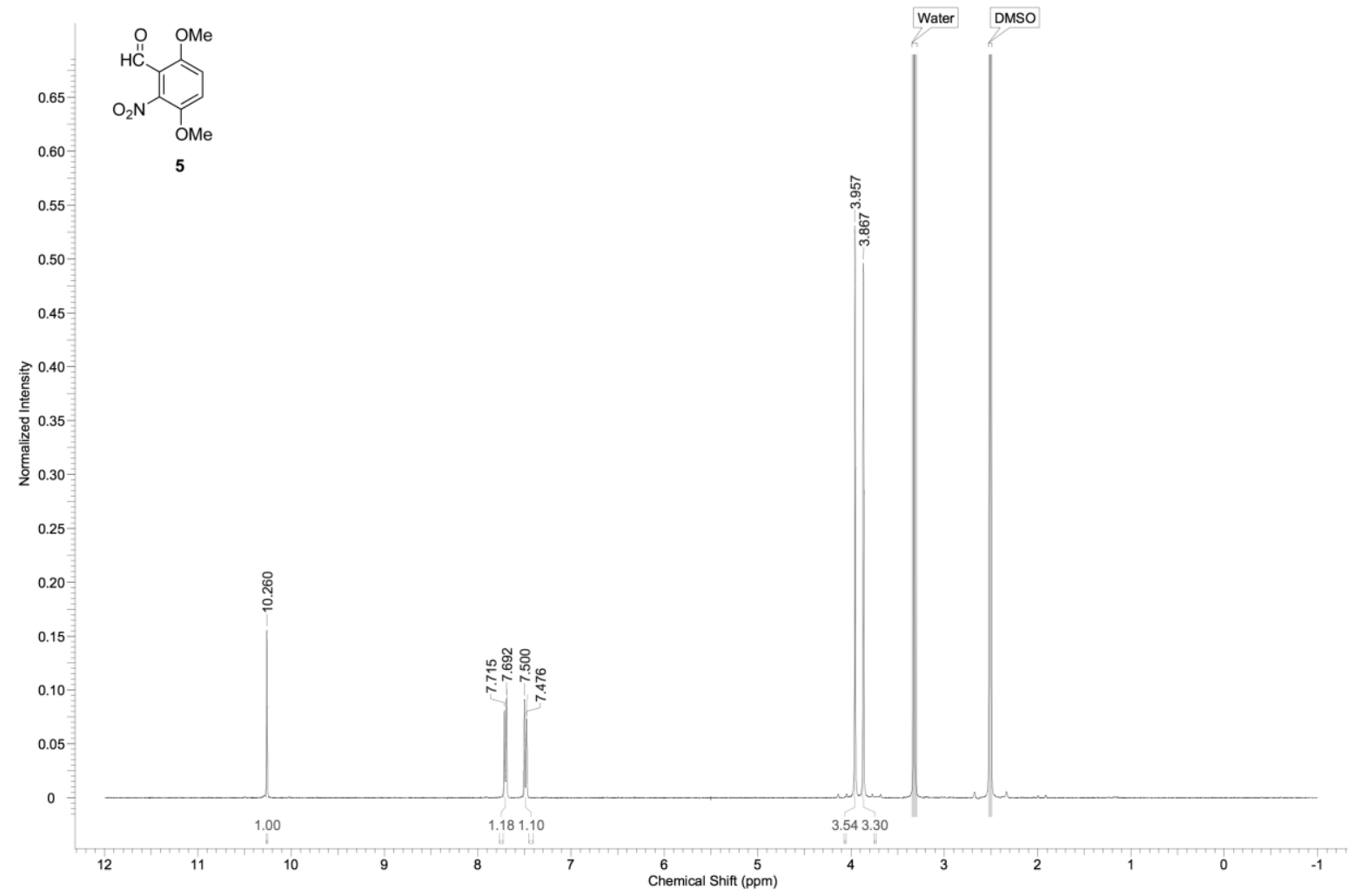




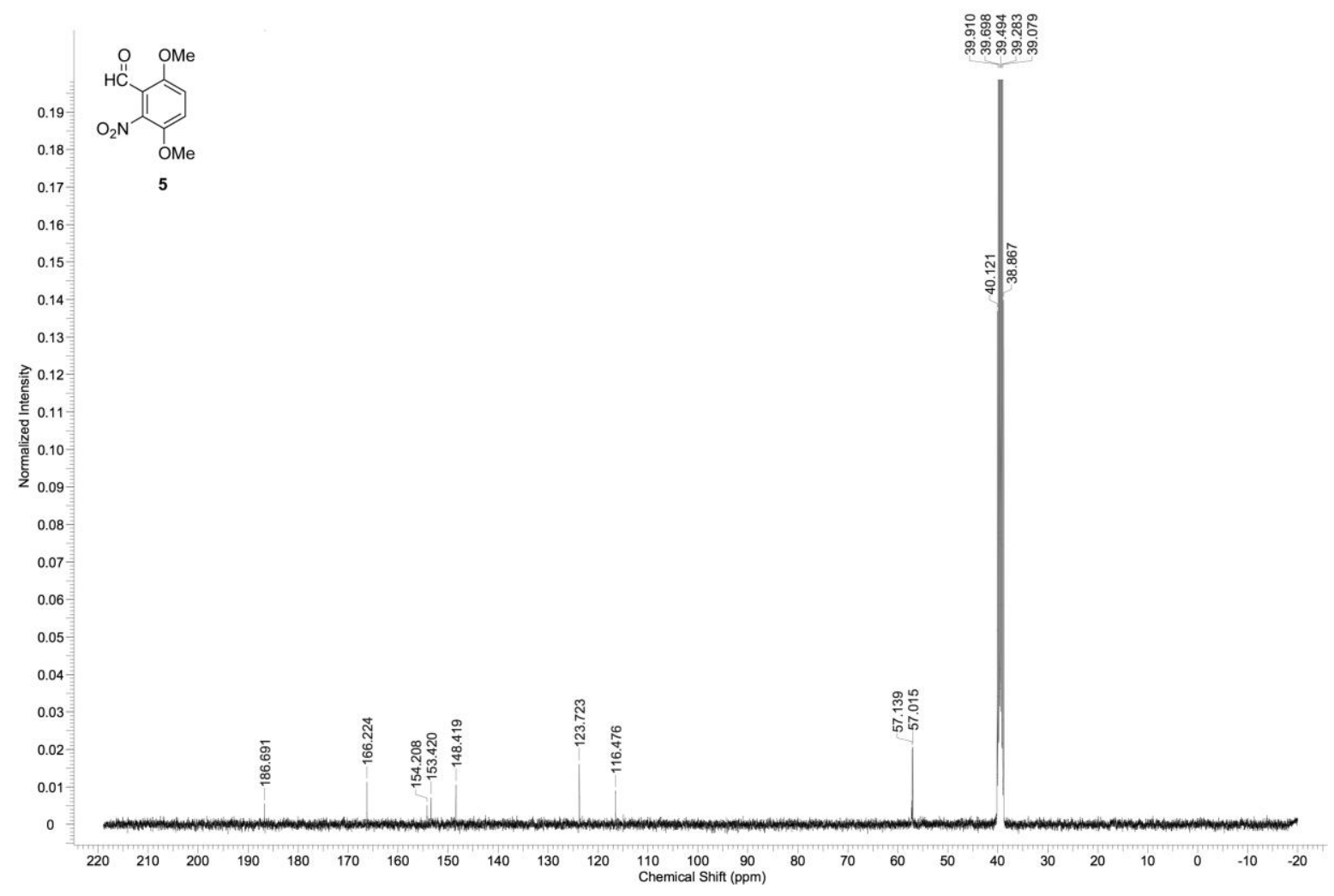




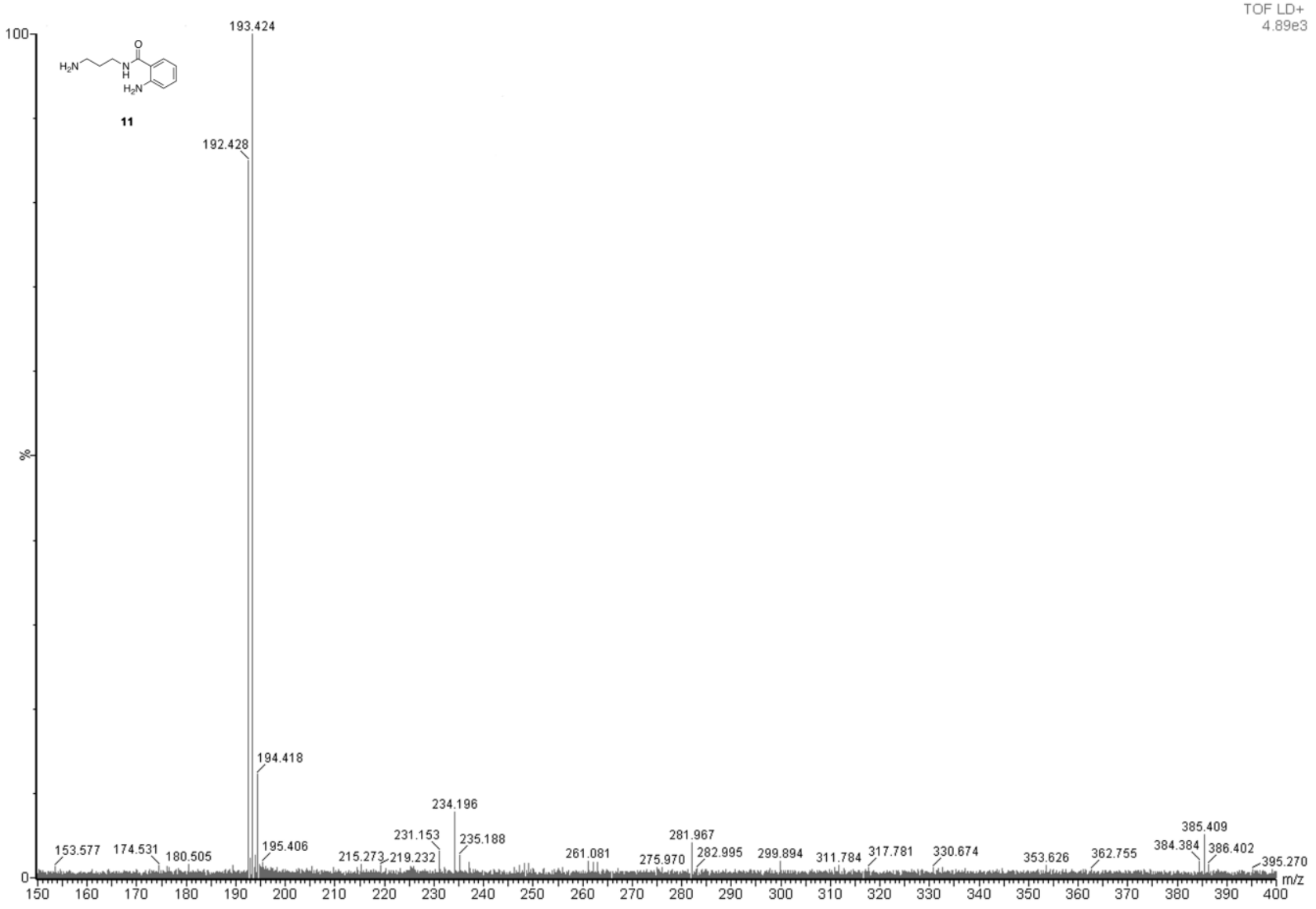




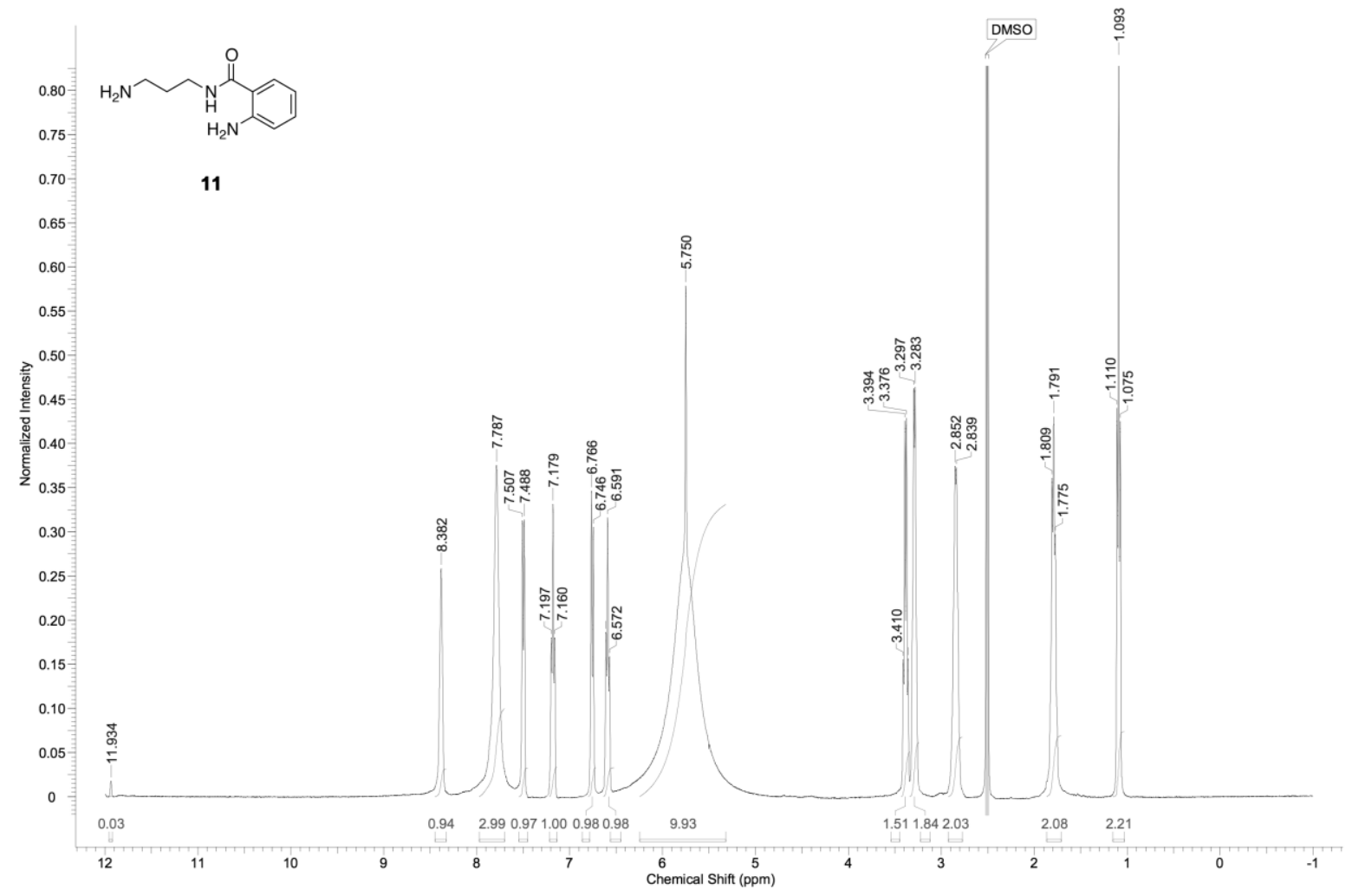




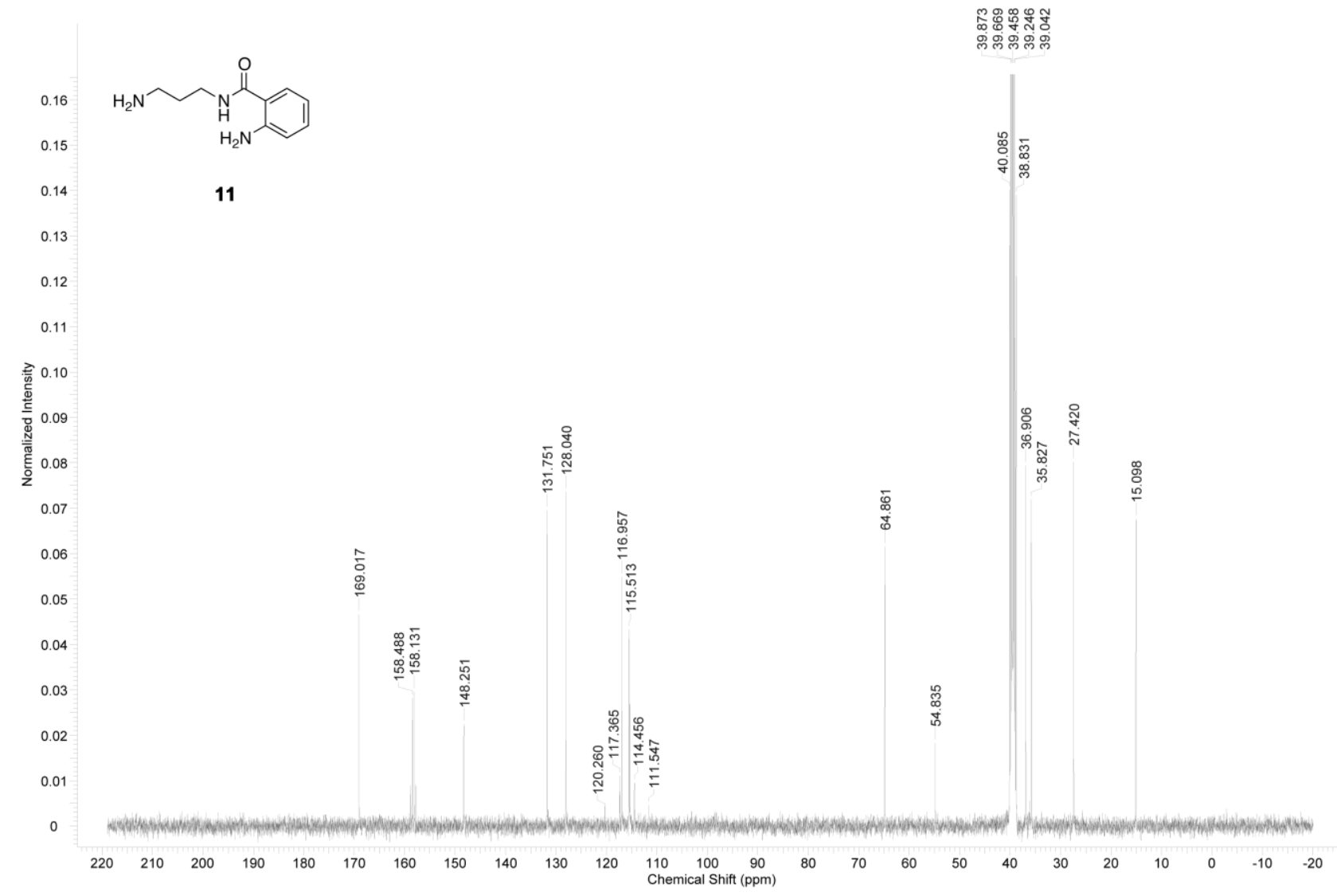




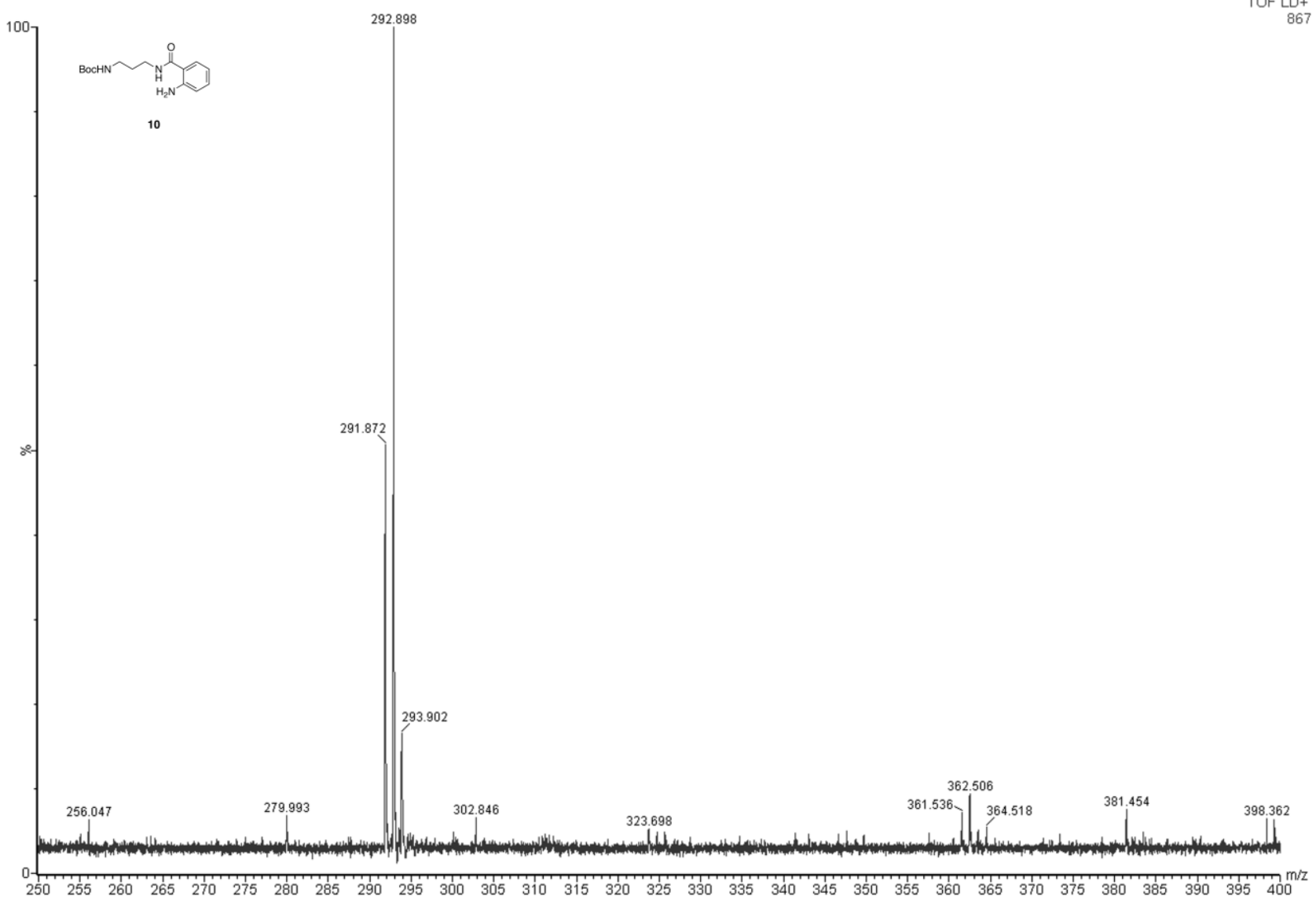




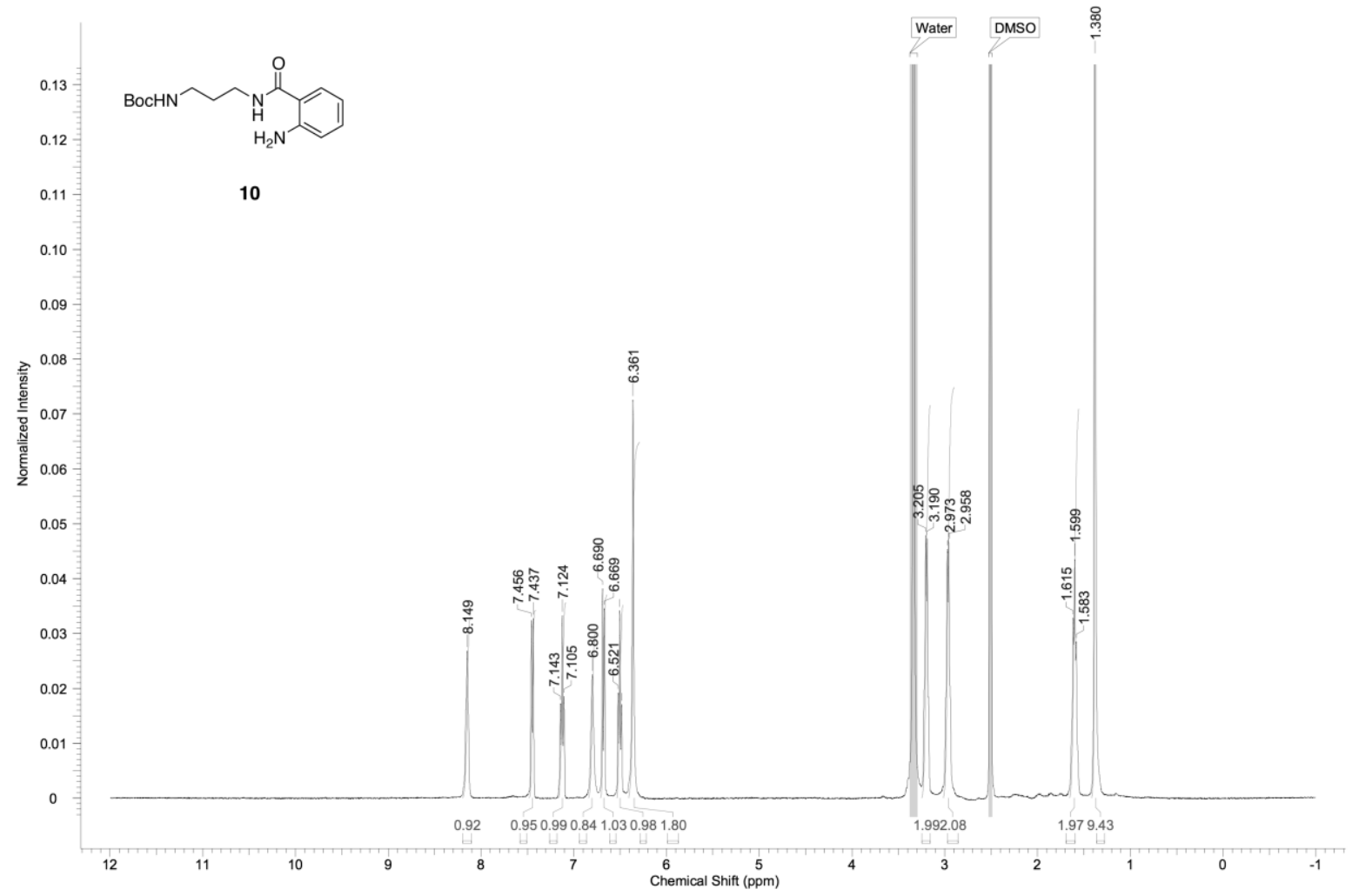




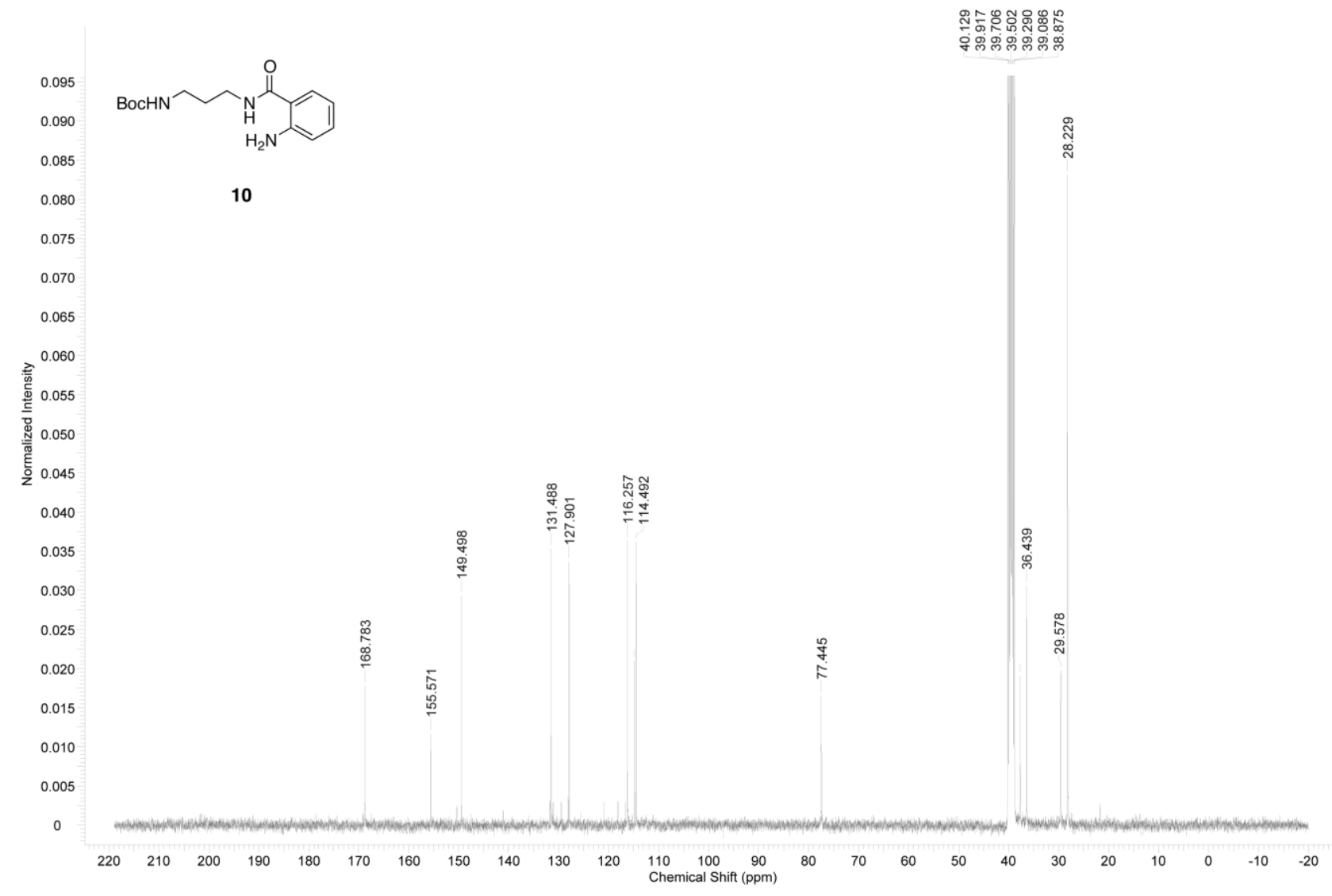




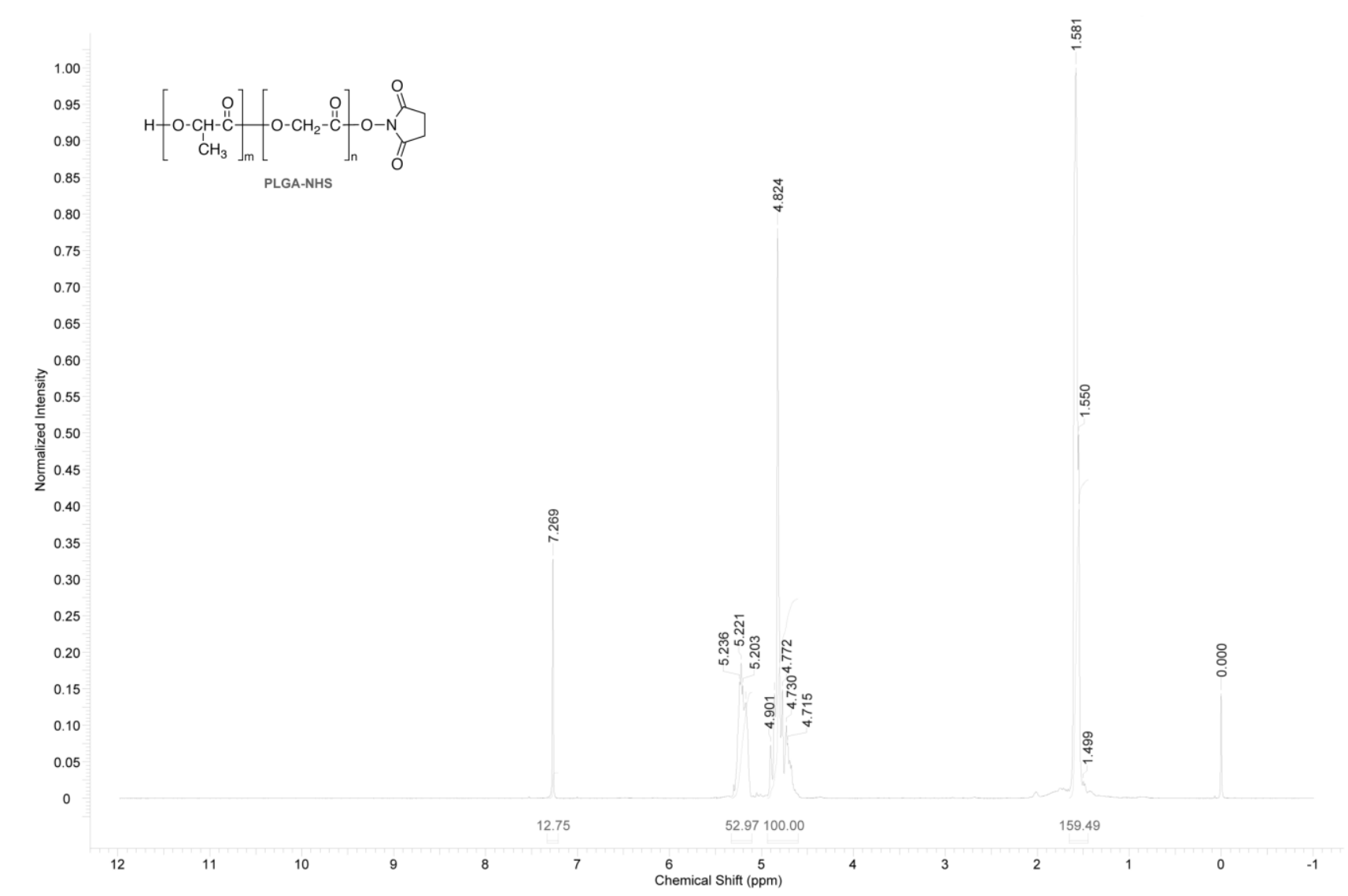




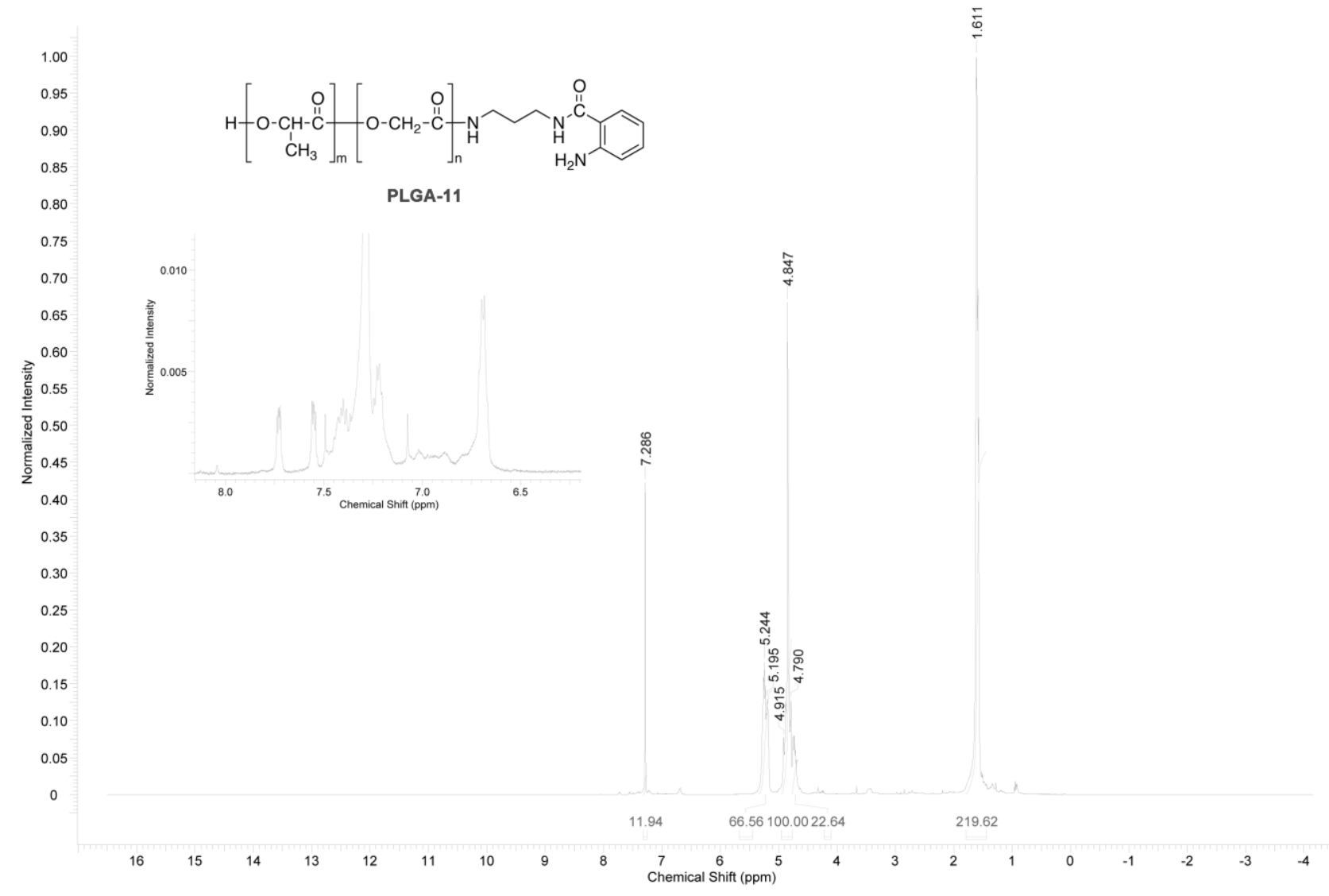




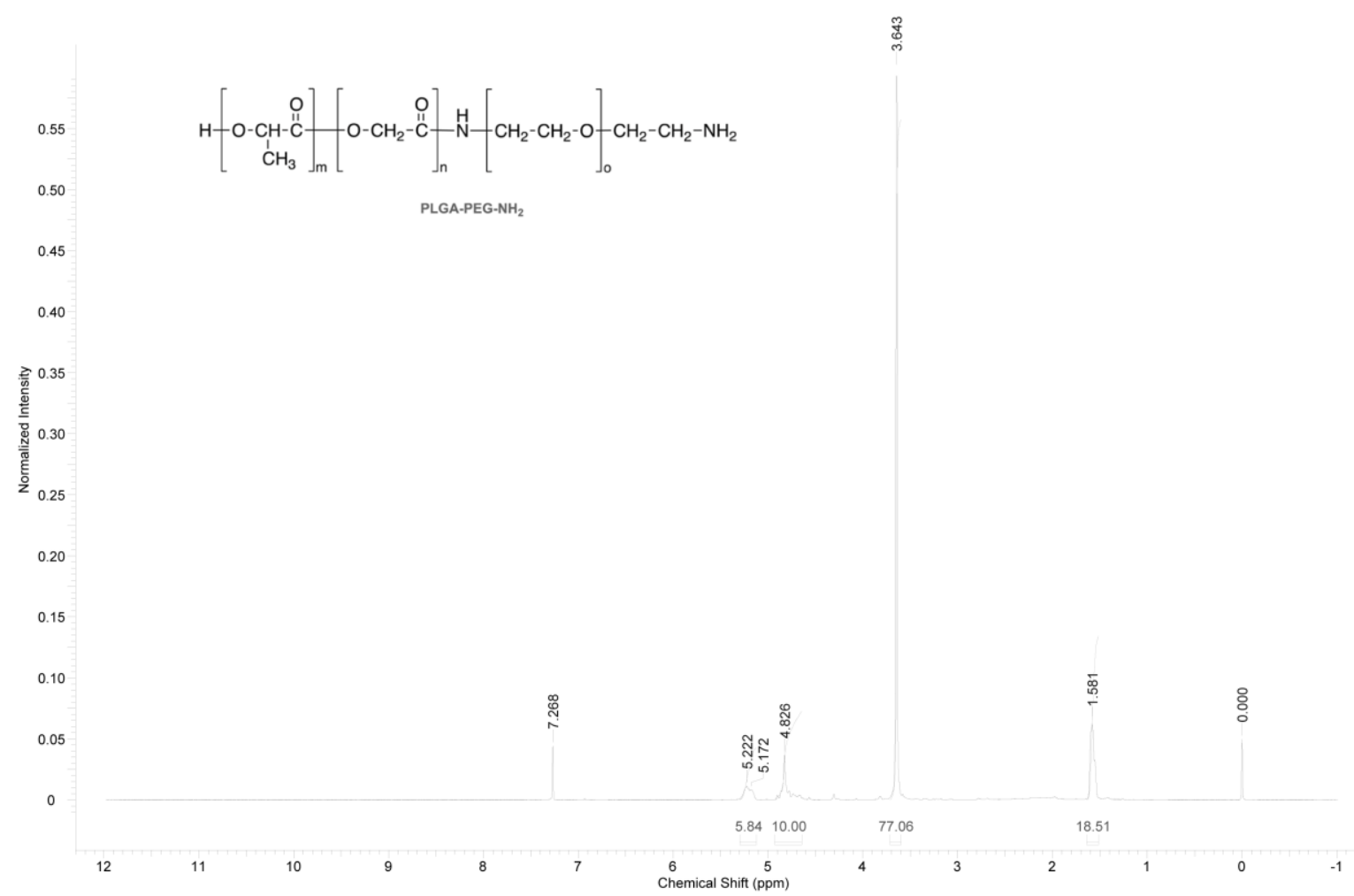




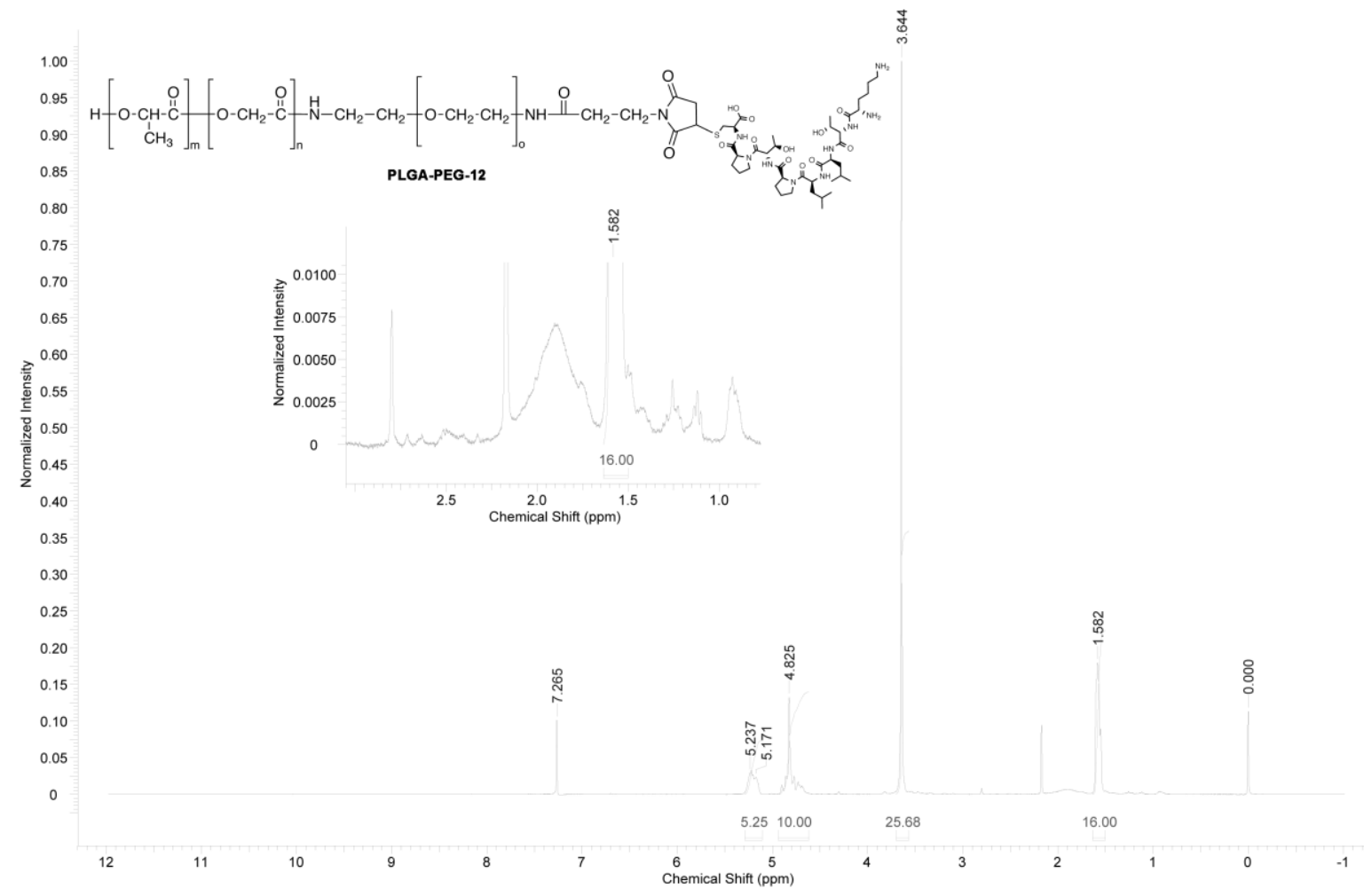




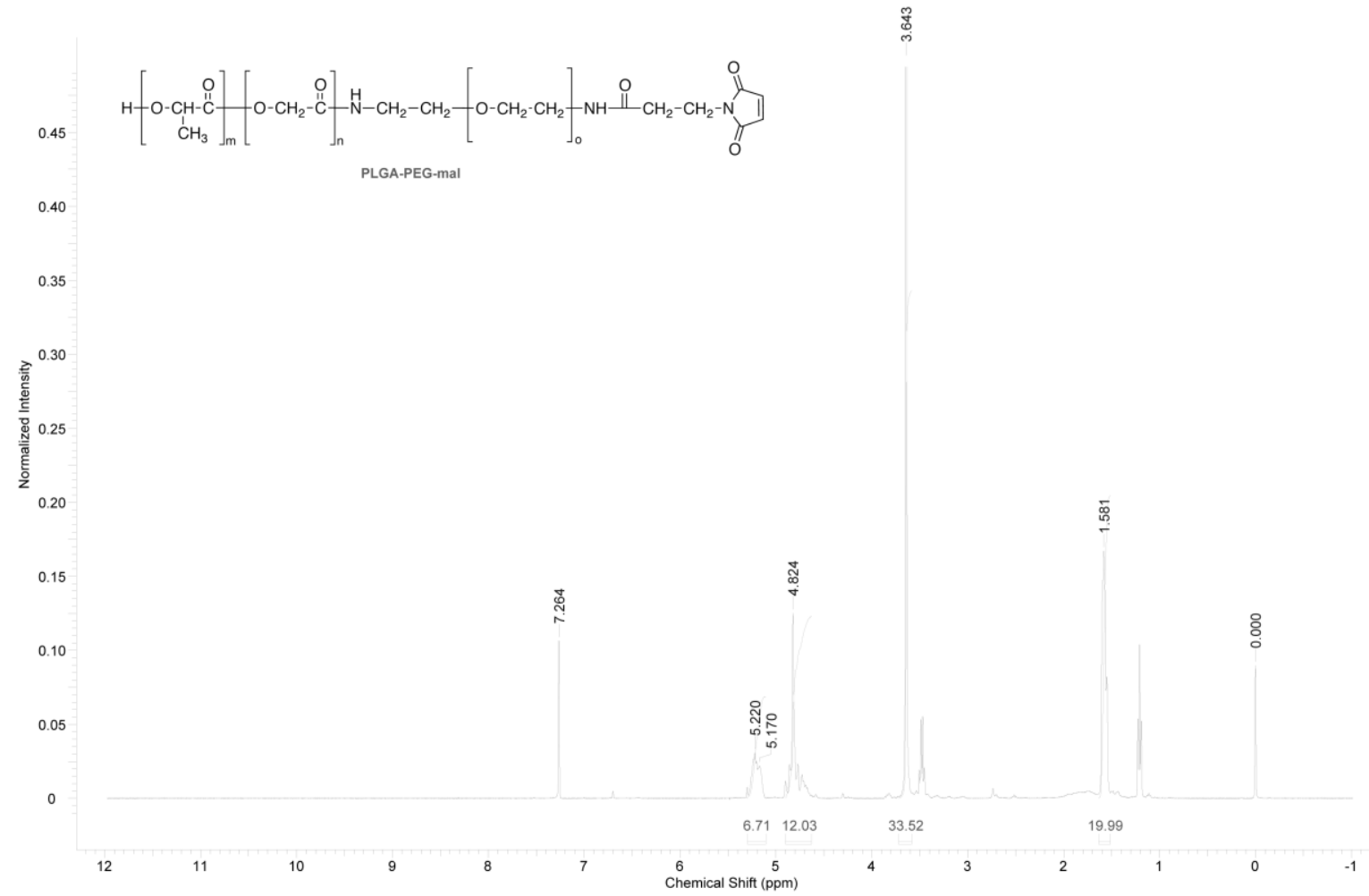




\section{Synthesis of peptide 12}

As mentioned in the Experimental (Material) section, the peptide 12 (peptide sequence: KTLLPTPC) was prepared by (Fmoc)-based solid-phase peptide synthesis ${ }^{1}$ using H-Cys(Trt)-CTC Resin, using the following method (provided by Caslo Laboratory, ApS).

All chemicals were purchased from commercial suppliers and used without further purification. Briefly, the Fmoc group for $\mathrm{N \alpha}$-protection was cleaved by 8 min treatment with $25 \%$ piperidine in DMF (0.1\% 1-hydroxybenzotriazole, HOBt) followed by the second treatment with the same reagent for $10 \mathrm{~min}$. After the Fmoc cleavage, the peptide-resin was washed with DMF $(\times 6)$. The next residue was then incorporated with the standard 1,3-diisopropylcarbodiimide DIPC/HOBt coupling protocol. ${ }^{2}$ After gentle agitation $(70 \mathrm{~min})$ and washing with DMF $(\times 6)$, part of the peptide-resin was subjected to the Kaiser test. ${ }^{3}$ If the Kaiser test shows positive, re-coupling was carried out. On completion of the assembly, the peptide-resin was successively washed with DMF $(\times 3), \mathrm{DCM}(\times 4)$ and then dried in vacuo.

Cleavage and deprotection: complete deprotection was achieved in a cleavage cocktail in $4 \mathrm{~h}$ at 30 ${ }^{\circ} \mathrm{C}$. Following the cleavage reaction, the mixture was precipitated in cold ether and dried at room temperature.

Purification and characterization: the peptide was purified by preparative RP-HPLC and quality controlled by analytical HPLC and mass spectrometry (please see the HPLC and MS reports for details in S30-S32).

Format: lyophilized trifluoroacetate salt (crystalline white powder)

Theoretical MW of peptide 12: 872.09; from ESI+ mass spectrometry certificate: $\mathrm{MW}[\mathrm{M}+\mathrm{H}]^{+}=$ 872.67, MW: 871.67. (S30).

Purity $($ HPLC $)=95.37 \%(\mathrm{Rt}: 10.52 \mathrm{~min})$, solvents ratio $(0-30 \mathrm{~min}): \mathrm{A}: \mathrm{B}=85: 15,40: 60,100: 0$;

$0.1 \%$ trifluoroacetic in $100 \%$ acetonitrile (A), $0.1 \%$ trifluoroacetic in $100 \%$ water (B)]. (S31).

Additionally, ${ }^{1} \mathrm{H}-\mathrm{NMR}$ spectrum was reported (S32).

\section{References}

1) Chan, W. C.; White, P. D. Fmoc Solid Phase Peptide Synthesis: A practical approach. Oxford University Press, 2000.

2) Valeur, E; Bradley, M. Amide bond formation: beyond the myth of coupling reagents. Chem. Soc. Rev. 2009, 38, 606-631.

3) Kaiser, E.; Colescot, R. L.; Bossinger, C. D.; Cook, P. I. Color test for detection of free terminal amino groups in solid-phase synthesis of peptides. Anal. Biochem. 1970, 34, 595598. 
Mass analysis for $\mathbf{1 2}$

\section{唄 BIOMATIK}

\section{Mass Spectrometry Report}

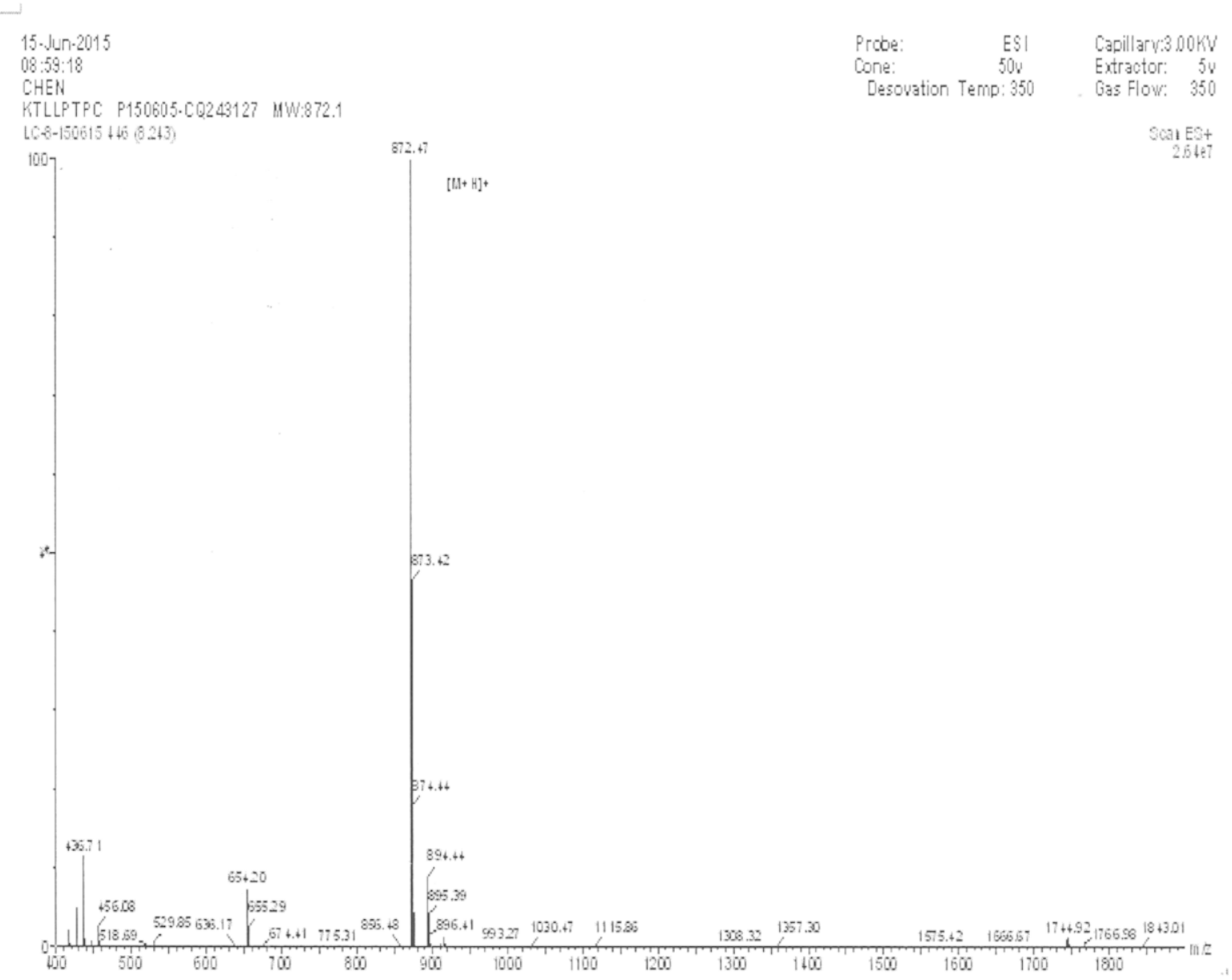


HPLC analysis for $\mathbf{1 2}$

\section{得 BIOMATIK}

\section{$\underline{\text { HPLC Report }}$}

Sample Description:

Structure: KTLLPTPC LC-8

Lot No:P150605-CQ243127

Column: 4.6mm*250mm, Inertsil ODS-SP

Solvent A: 0. 1\% Trifluoroacetic in 100\% Acetonirile

Solvent B: $0.1 \%$ Trifluoroacetic in $100 \%$ Water

Gradient :

$\begin{array}{rcr} & \text { A } & \text { B } \\ 0.01 \mathrm{~min} & 22 \% & 78 \% \\ 25.00 \mathrm{~min} & 47 \% & 53 \% \\ 25.01 \mathrm{~min} & 100 \% & 0 \% \\ 30.00 \mathrm{~min} & \text { Stop } & \end{array}$

Flow rate: $1.0 \mathrm{ml} / \mathrm{min}$

Wavelength:220nm

Volume: $10 \mu 1$

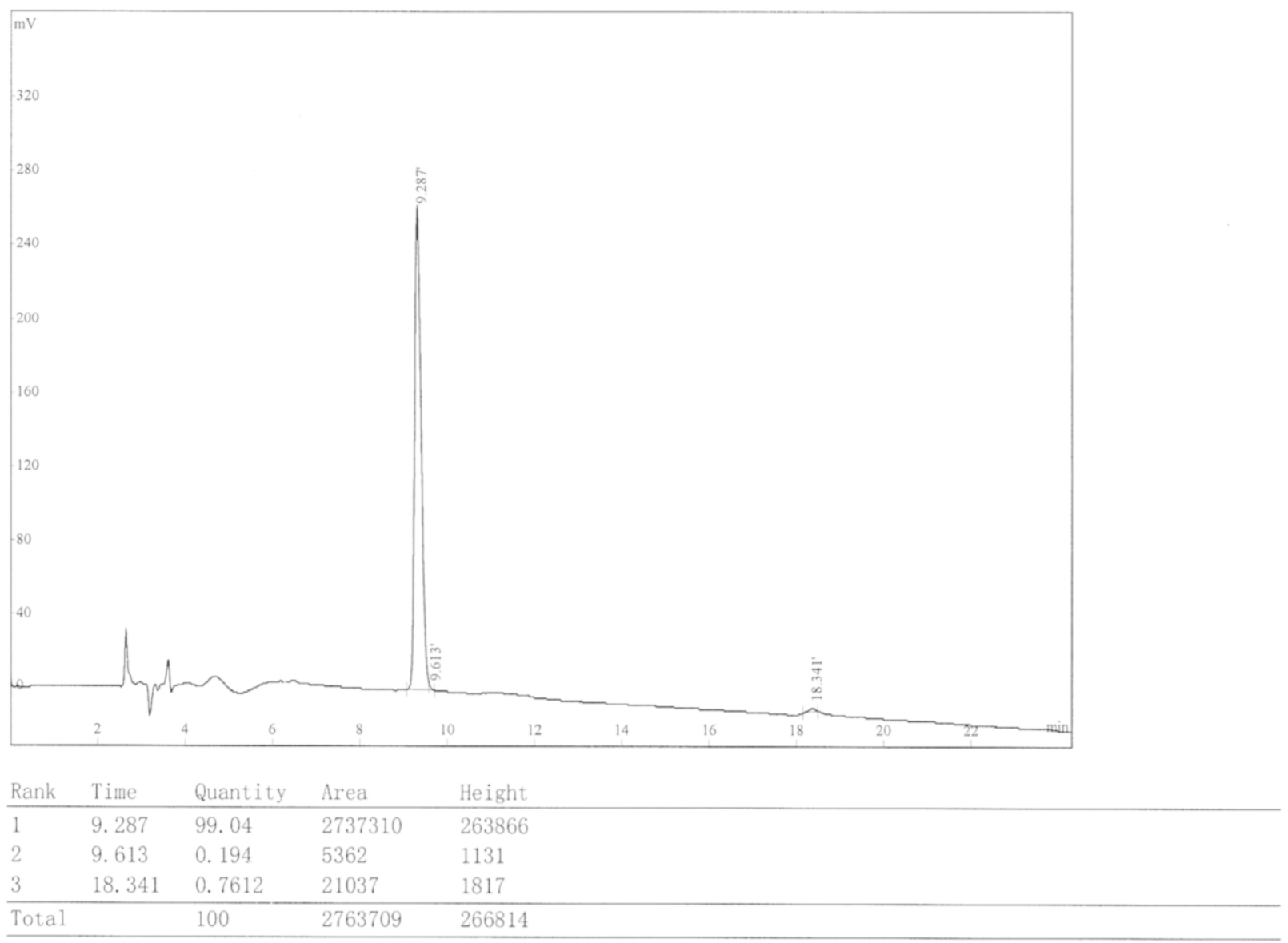




\section{${ }^{1} \mathrm{H}-\mathrm{NMR}$ spectra for $\mathbf{1 2}$}

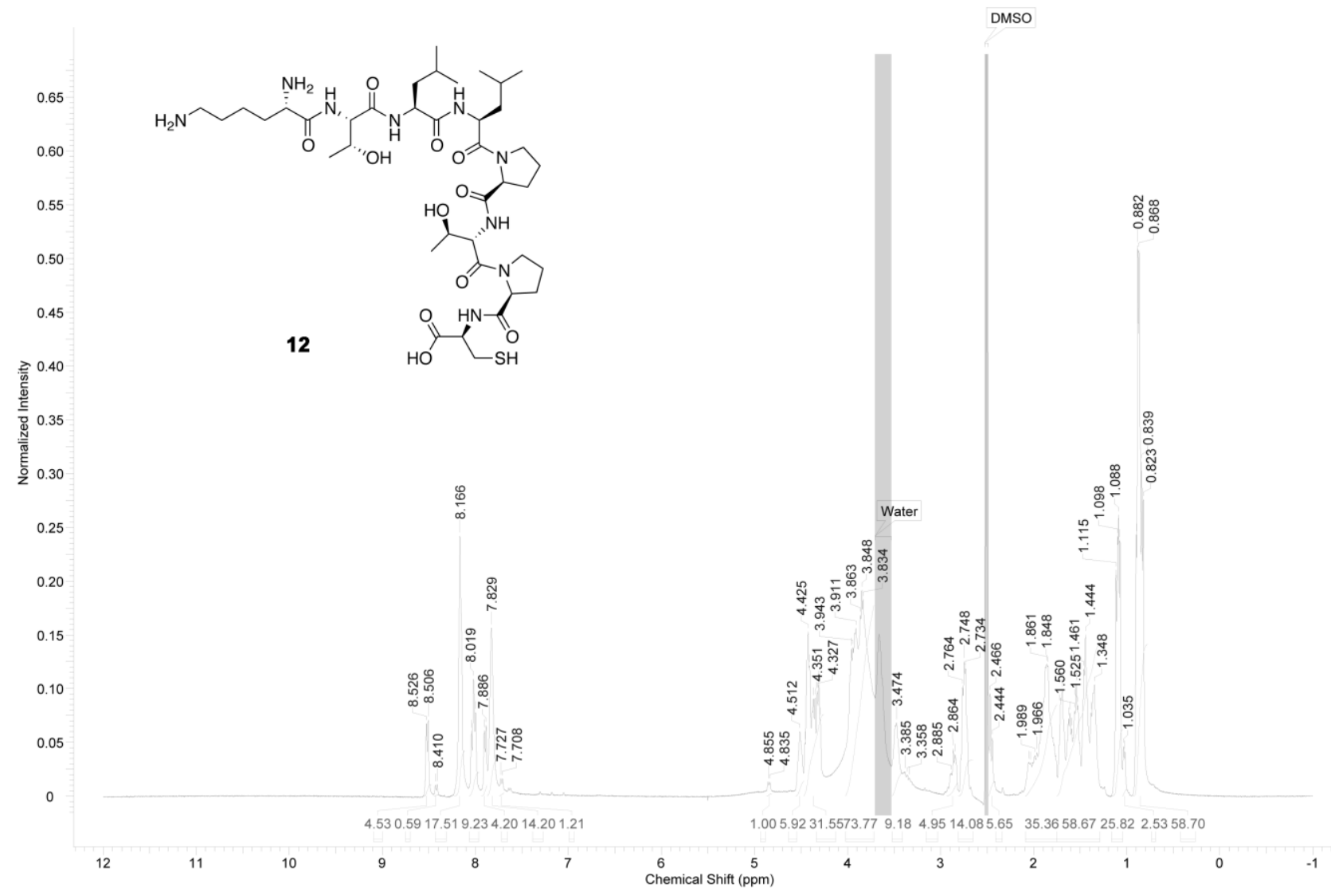


Table S33. Elemental analysis data of synthesized compounds.

\begin{tabular}{|c|c|c|c|c|c|c|c|}
\hline \multirow{2}{*}{ Compound } & \multirow{2}{*}{ Molecular Formula } & \multicolumn{3}{|c|}{ Calculated } & \multicolumn{3}{|c|}{ Found } \\
\hline & & $\% \mathrm{C}$ & $\% \mathbf{H}$ & $\mathbf{N}$ & $\% \mathrm{C}$ & $\% \mathbf{H}$ & $\% \mathbf{N}$ \\
\hline 1 & $\mathrm{C}_{21} \mathrm{H}_{13} \mathrm{~N}_{3} \mathrm{O}_{3}$ & 70.98 & 3.69 & 11.83 & 70.64 & 3.97 & 11.70 \\
\hline 2 & $\mathrm{C}_{8} \mathrm{H}_{4} \mathrm{~N}_{2} \mathrm{O}_{2} \cdot 0.25 \mathrm{H}_{2} \mathrm{O}$ & 58.36 & 2.75 & 17.02 & 58.11 & 3.01 & 16.86 \\
\hline 7 & $\mathrm{C}_{10} \mathrm{H}_{10} \mathrm{~N}_{2} \mathrm{O}_{2}$ & 63.15 & 5.32 & 14.73 & 62.99 & 5.50 & 14.89 \\
\hline 6 & $\mathrm{C}_{11} \mathrm{H}_{13} \mathrm{~N}_{3} \mathrm{O}_{6}$ & 46.65 & 4.63 & 14.84 & 46.73 & 4.42 & 15.13 \\
\hline 5 & $\mathrm{C}_{9} \mathrm{H}_{9} \mathrm{NO}_{5}$ & 51.19 & 4.30 & 6.63 & 51.08 & 4.45 & 6.65 \\
\hline 11 & $\mathrm{C}_{10} \mathrm{H}_{15} \mathrm{~N}_{3} \mathrm{O} \cdot \mathrm{CF}_{3} \mathrm{COOH} \bullet 0.60 \mathrm{H}_{2} \mathrm{O}$ & 45.31 & 5.45 & 13.21 & 45.18 & 5.59 & 13.04 \\
\hline 10 & $\mathrm{C}_{15} \mathrm{H}_{23} \mathrm{~N}_{3} \mathrm{O}_{3}$ & 61.41 & 7.90 & 14.32 & 61.27 & 8.02 & 14.38 \\
\hline
\end{tabular}


Table S34. Average diameter, polydispersity index, zeta potential, encapsulation efficiency and yield of production of 6-coumarin (6C) loaded NPs.

\begin{tabular}{cccccc}
\hline Formulation & $\begin{array}{c}\text { Average } \\
\text { diameter } \\
(\mathbf{n m})\end{array}$ & $\begin{array}{c}\text { Polydispersity } \\
\text { index }\end{array}$ & $\begin{array}{c}\text { Zeta } \\
\text { Potential } \\
(\mathbf{m V})\end{array}$ & $\begin{array}{c}\text { Encapsulation } \\
\text { efficiency }(\%)\end{array}$ & $\begin{array}{c}\text { Yield of } \\
\text { production } \\
(\%)\end{array}$ \\
\hline PLGA-A-(6C) & $165.7 \pm 10.6^{*}$ & $0.12 \pm 0.02$ & $-19.5 \pm 1.1$ & $19.33 \pm 2.65$ & $65.31 \pm 4.37$ \\
$\begin{array}{c}\text { PLGA-11-(6C) } \\
\begin{array}{c}{ }^{a} \text { PLGA-PEG- } \\
\text { NH }\end{array}\end{array}$ & $210.4 \pm 12.5^{*}$ & $0.10 \pm 0.01$ & $14.4 \pm 1.2$ & $18.53 \pm 2.84$ & $63.98 \pm 2.03$ \\
$\begin{array}{c}{ }^{a} \text { PLGA-PEG-12- } \\
(\mathbf{6 C})\end{array}$ & $365.5 \pm 31.2$ & $0.13 \pm 0.02$ & $16.0 \pm 2.0$ & $21.02 \pm 2.64$ & $70.24 \pm 4.01$ \\
\hline
\end{tabular}

${ }^{a}$ Formulation been performed with the addition of PCL polymer (see on the experimental section). Values presented are the mean \pm SD of three preparations.

(*) Significant differences from PLGA-PEG batches $(\mathrm{p}<0.05)$. 
Table S36. GPC-SEC analyses (molecular weight averages, polydispersity and refractive indexes) for PLGA-A, PLGA-PEG-NH 2 and PLGA-PEG-12 polymers.

\begin{tabular}{|c|c|c|c|}
\hline & PLGA-A & PLGA-PEG-NH & PLGA-PEG-12 \\
\hline $\operatorname{Mn}(\mathbf{D a})^{\mathrm{a}}$ & 16.031 & 14197 & 20005 \\
\hline Mw (Da) ${ }^{b}$ & 16.615 & 17986 & 23434 \\
\hline $\mathbf{M z}(\mathbf{D a})^{\mathrm{c}}$ & 16.199 & 22817 & 26278 \\
\hline$M p(D a)^{d}$ & 16.215 & 16572 & 25485 \\
\hline $\mathrm{Mw} / \mathbf{M n}^{\mathrm{e}}$ & 1.05 & 1.267 & 1.171 \\
\hline $\mathrm{dn} / \mathrm{dc} \mathrm{c}^{\mathrm{f}}$ & 0.0169 & 0.017 & 0.016 \\
\hline Conc $(\mathrm{mg} / \mathrm{mL})$ & 22.5 & 16.5 & 22.0 \\
\hline
\end{tabular}

${ }^{a}$ Number average molecular weight: $\mathrm{Mn} .{ }^{b}$ Weight average molecular weight: Mw. ${ }^{c}$ Higher average molecular weights: Mz. ${ }^{\mathrm{d}}$ Molecular weight of the highest peak: Mp. ${ }^{\mathrm{e}}$ Polydispersity index (PDI): $\mathrm{Mw} / \mathrm{Mn} .{ }^{\mathrm{f}}$ Refractive Index Increment: dn/dc.

\section{GPC-SEC analysis procedure}

The samples were analyzed by an integrated GPC/SEC system using a Viscotek 270 dual detector instrument (Malvern Instruments Ltd, Worcestershire, UK), with light scattering and viscometer detectors. Analyses were conducted on a chromatograph equipped with a Knauer isocratic pump. The mobile phase was constituted by dichloromethane (with flow of $1.0 \mathrm{~mL} / \mathrm{min}$ ), while the stationary phase consists of two columns: Resipor - PL (400000-500 Da) and Tosoh (20000-500 Da). The determination of the molecular weight distributions was obtained by OmniSEC software (Viscotek). The calculation of molecular weights with absolute method has been obtained by calibration with polystyrene standards with a molecular weight of 72,000 Da. The dn/dc value of each sample was determined by considering a purity higher than $99 \%$. 

conditions) of PLGA-A, PLGA-PEG-NH 2 and PLGA-PEG-12 polymers.
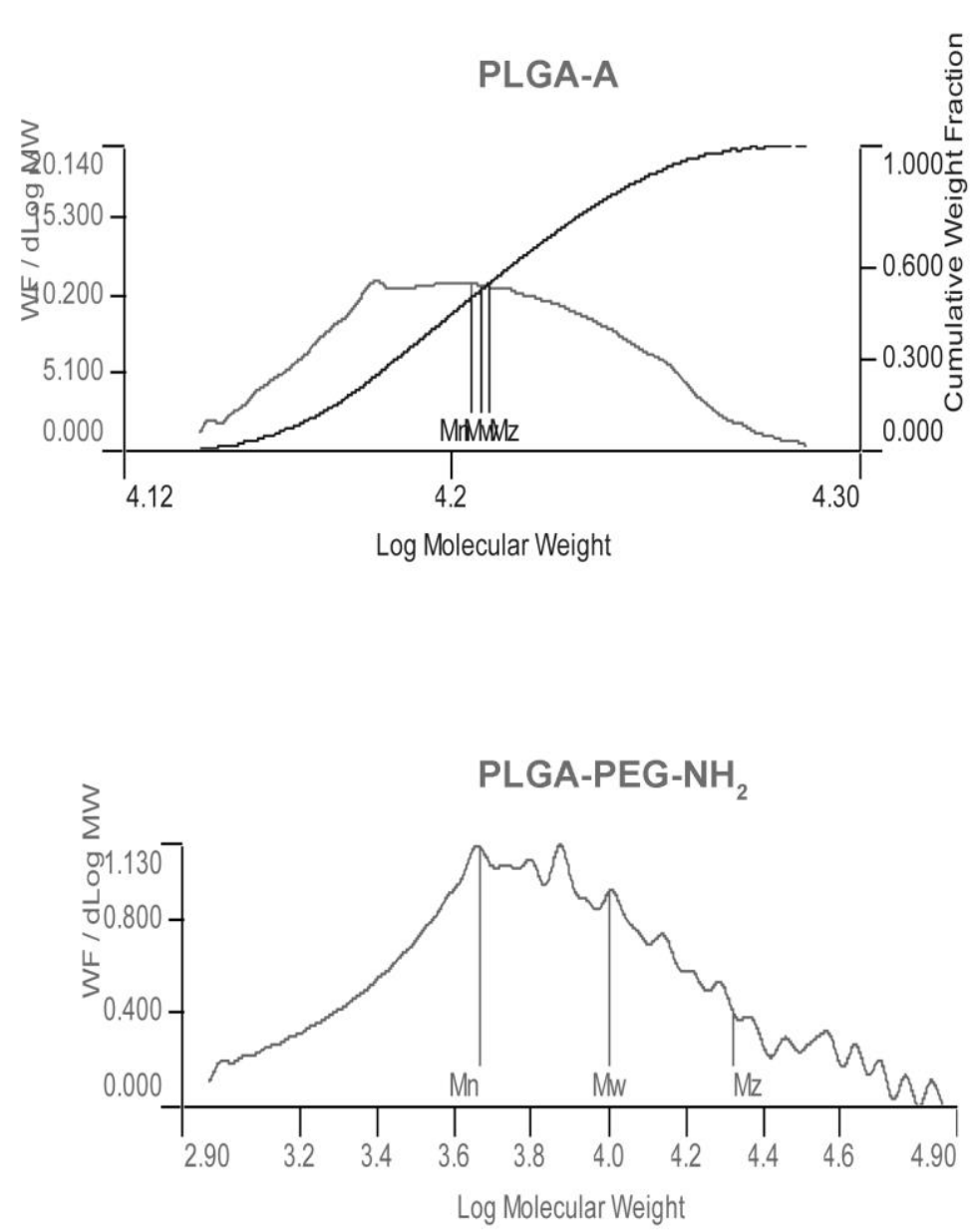

Log Molecular Weight
Data File:PLGA-A

Peak RV - $(\mathrm{ml}) \quad 16.853$

$\mathrm{Mn}$ - (Daltons) 16.031

$\mathrm{Mw}$ - (Daltons) 16.615

$\mathrm{Mz}$ - (Daltons) 16.199

Mp - (Daltons) 16.115

$\mathrm{Mw} / \mathrm{Mn} \quad 1.05$

IV $-(\mathrm{dl} / \mathrm{g}) \quad 0.0146$

$\mathrm{Rh}-(\mathrm{nm}) \quad 1.730$

RI Area - (mvml) 17.80

Sample Parameters Input

Sample Conc - $(\mathrm{mg} / \mathrm{ml}) 22.500$

Sample Recovery (\%) $\quad 0.000$

$\mathrm{dn} / \mathrm{dc}-(\mathrm{ml} / \mathrm{g}) \quad 0.0169$

Solvent

DCM

Column Set

1.000

Flow Rate - $(\mathrm{ml} / \mathrm{min})$

Inj Volume - (ul)

Volume Increment - (ml) 0.00333

Detector Temp. - $(\operatorname{deg} C) 22.0$

Column Temp. - (deg C) 35.0

Data File:PLGA-PEG-NH

Peak RV - (ml) 17.347

$\mathrm{Mn}$ - (Daltons) 14.197

Mw - (Daltons) 17.986

$\mathrm{Mz}$ - (Daltons) 22.817

Mp - (Daltons) 16.572

$\mathrm{Mw} / \mathrm{Mn} \quad 1.267$

IV - (dl/g)

$\mathrm{Rh}-(\mathrm{nm}) \quad 6.574$

Sample Parameters Input Calculated

Sample Conc - $(\mathrm{mg} / \mathrm{ml}) \quad 16.500 \quad 0.000$

$\begin{array}{lll}\text { Sample Recovery (\%) } & 0.000 & 33.31\end{array}$

$\mathrm{dn} / \mathrm{dc}-(\mathrm{ml} / \mathrm{g}) \quad 0.0170 \quad 0.0000$

Solvent DCM

Column Set

Flow Rate - $(\mathrm{ml} / \mathrm{min}) \quad 1.000$

Inj Volume - (ul) 50.0

Volume Increment - (ml) 0.00333

Detector Temp. - (deg C) 22.0

Column Temp. - (deg C) 35.0

Data File:PLGA-PEG-12

Peak RV - (ml) 13.843

Mn - (Daltons) 20.005

Mw - (Daltons) 23.434

$\mathrm{Mz}$-(Daltons) 26.278

Mp-(Daltons) 25.485

$\mathrm{Mw} / \mathrm{Mn} \quad 1.171$

IV - (dl/g) $\quad 0.0107$

$\mathrm{Rh}-(\mathrm{nm}) \quad 1.231$

Mark-Houwink a 2.257

Mark-Houwink logK - 11.944

Sample Parameters Input

Sample Conc - $(\mathrm{mg} / \mathrm{ml}) 22.000$

Sample Recovery (\%) $\quad 0.000$

$\mathrm{dn} / \mathrm{dc}-(\mathrm{ml} / \mathrm{g})$

0.0160

Calculated

0.000

39.886

Solvent DCM

0.0000

Column Set GMHxl

Flow Rate - $(\mathrm{ml} / \mathrm{min}) \quad 1.000$

Inj Volume - (ul)

50.0

detector Temp. - (deg C) 22.0

Column Temp. - (deg C) 35.0 